\title{
Evaluation of Weather Noise and Its Role in Climate Model Simulations*
}

\author{
HuA CHEN \\ Department of Atmospheric Oceanic and Earth Sciences, George Mason University, Fairfax, Virginia \\ EDWIN K. SCHNEIDER \\ Department of Atmospheric Oceanic and Earth Sciences, George Mason University, Fairfax, Virginia, \\ and Center for Ocean-Land-Atmosphere Studies, Calverton, Maryland \\ BEN P. KIRTMAN \\ Division of Meteorology and Physical Oceanography, Rosenstiel School for Atmospheric and Marine \\ Science, University of Miami, Miami, Florida \\ IOANA COLFESCU \\ Department of Atmospheric Oceanic and Earth Sciences, George Mason University, Fairfax, Virginia
}

(Manuscript received 23 May 2012, in final form 10 October 2012)

\begin{abstract}
The relationship between coupled atmosphere-ocean general circulation model simulations and uncoupled simulations made with specified SST and sea ice is investigated using the Community Climate System Model, version 3. Experiments are carried out in a perfect model framework. Two closely related questions are investigated: 1) whether the statistics of the atmospheric weather noise in the atmospheric model are the same as in the coupled model, and 2) whether the atmospheric model reproduces the SST-forced response of the coupled model.

The weather noise in both the coupled and uncoupled simulations is found by removing the forced response, as determined from the uncoupled ensemble, from the atmospheric field. The weather-noise variance is generally not distinguishable between the coupled and uncoupled simulations. However, variances of the total fields differ between the coupled and uncoupled simulations, since there is constructive or destructive interference between the SST-forced response and weather noise in the coupled model but no correlation between the SST-forced and weather-noise components in the uncoupled model simulations.

Direct regression estimates of the forced response show little difference between the coupled and uncoupled simulations. Differences in local correlations are explained by weather noise because weather noise forces SST in the coupled simulation only.

The results demonstrate and explain an important intrinsic difference in precipitation statistics between the coupled and uncoupled simulations. This difference could have consequences for the design of dynamical downscaling experiments and for tuning general circulation models.
\end{abstract}

* Supplemental information related to this paper is available at the Journals Online website: http://dx.doi.org/10.1175/JCLID-12-00292.s1.

Corresponding author address: Hua Chen, 4041 Powder Mill Road, Suite 302, Calverton, MD 20705.

E-mail: chen@cola.iges.org

\section{Introduction}

The atmosphere and ocean are coupled in two directions: on the one hand, the atmosphere is forced by the ocean through the SST; on the other hand, the ocean is forced by the atmosphere through surface fluxes: surface heat flux (shortwave radiation, longwave radiation, sensible and latent heat flux), momentum flux 
(zonal and meridional wind stress), and freshwater flux (precipitation and evaporation). It has been recognized that atmospheric models forced by specified SST, in which the coupling is only one way (referred to hereafter as uncoupled models), have substantially different properties from coupled models, where the two-way coupling is correctly represented (Gallimore 1995; Manabe and Stouffer 1996; Bladé 1997; Bhatt et al. 1998). In particular, the variances of some quantities (air temperature, specific humidity) were larger in the coupled model than in the uncoupled model; the variances of other quantities, especially net surface heat flux (NHF), were smaller; and there was enhanced persistence of atmospheric anomalies in the coupled model.

These results have been explained by Barsugli and Battisti (1998, hereafter BB98) using a simple linear twovariable model consisting of a stochastically forced onepoint atmosphere heat budget equation characterized by an atmospheric temperature, locally coupled to a one-point slab ocean heat budget equation characterized by an ocean temperature (SST). This is the simplest possible nontrivial representation of a coupled model with the atmosphere model-ocean model structure of a current-day coupled general circulation model (CGCM). The model reduces to the one-variable stochastically forced ocean model of Hasselmann (1976) for time scales at which the heat capacity of the atmosphere can be ignored. The BB98 model is a good approximation for extratropical regions where stochastic atmospheric variability is the primary driver of SST anomalies, but not for the regions where ocean dynamics plays more important roles (e.g., the equatorial Pacific and western boundary current regions) or where atmospheric variability is strongly influenced by remote oceanic forcing through teleconnections (e.g., the tropical Indian Ocean). The relative role of local and remote SSTs also varies with the evolution of ENSO events over the tropical Indian Ocean (e.g., Xie et al. 2009).

In BB98, the SST responds to the heat flux produced by the difference between the atmosphere and ocean temperatures. When the atmosphere and ocean are coupled, the stochastic forcing, which we term "weather noise," forces the SST variability, while the SST-forced response of the atmosphere damps the SST variability. This leads to interference between the weather noise and the forced response-destructive interference for the NHF and constructive interference for the atmospheric temperature. When the atmosphere and ocean are decoupled by forcing the atmosphere with a specified SST evolution, while still including a stochastic forcing in the atmosphere, the weather noise and the forced response are temporally uncorrelated. Therefore, the ratio of the NHF variance in the coupled model to that in the atmospheric model forced by the SST obtained from a coupled model simulation is less than one, while the ratio of the coupled to uncoupled atmospheric temperature variance is greater than one. Physically, the forced response in the uncoupled model is the same as in the coupled model, and the weather noise in the uncoupled model has the same variance as in the coupled model but is uncorrelated with that in the coupled model (representing the chaotic dynamics of the atmosphere), and is thus uncorrelated with the SST.

Saravanan (1998) performed a regression analysis of the local relationship between NHF and SST patterns in the North Pacific and North Atlantic in a long CGCM simulation and an ensemble of atmospheric general circulation models (AGCMs) forced by observed SST [Atmospheric Model Intercomparison Project (AMIP)type simulations; Gates et al. 1999]. It was found that the correlation between NHF anomalies and SST anomalies in the uncoupled simulations was opposite in sign to that found in the coupled simulation. This behavior occurs in the context of the BB98 model due to weathernoise forcing of the SST anomalies. Energetically, from the simple model SST equation, the production of SST variance in the coupled model by the stochastic forcing is balanced by damping of SST variance by the forced response to the SST anomalies.

The SST-forced response from the CGCM or from the SST-forced AGCM cannot be found directly, as the weather noise cannot be eliminated from the individual model simulations. However, the weather noise can be filtered out by taking the ensemble mean of a large ensemble AGCM simulations with the common SST forcing, as long as the weather noise in the ensemble members is statistically independent (e.g., is white noise with the same variance) (Bretherton and Battisti 2000).

The methodology of extracting weather noise from simulations or analyses of observations by removing the SST-forced component, taken as the ensemble mean of an ensemble of AMIP-type AGCM simulations, is intuitively appealing, and has been discussed by Saravanan (1998) and Frankignoul (1999). Investigations that have applied this methodology include those of Schneider and Fan (2007), Fan and Schneider (2012), and Schneider and Fan (2012), who used it to determine the weathernoise surface fluxes and then forced an interactive ensemble (IE) CGCM (Kirtman and Shukla 2002) with the weather noise to isolate the noise-forced SST variability. Kirtman et al. (2011) examined weather noise in IE simulations with and without external forcing. Hurrell et al. (2009) compared the SST-forced and free (weather noise) variability in simulations made with various AGCMs forced by the observed SST and found substantial model dependence. 
However, results from other studies, some of which are described below, appear to challenge a major assumption behind this procedure. The most convincing of these studies eliminate model bias and observational uncertainty issues by comparing the SST-forced response in perfect model experiments, and imply that the SST-forced response of the AGCM ensemble does not reproduce the SST-forced response of the parent CGCM simulation. Since this assumption is a cornerstone of our ongoing research to isolate the weathernoise-forced SST variability, we have reexamined the results from the other studies and have tested whether, under ideal perfect model and perfect data conditions, the noise extraction procedure satisfies the conditions of the BB98 model. These conditions are that when an uncoupled model (AGCM) is forced by the SST from a coupled (CGCM) simulation, 1) the weather noise is statistically the same in the coupled and uncoupled simulations and 2) that the SST-forced solution is identical in the coupled and uncoupled simulations. In BB98, constant noise variance was assumed, and the linearity of the model led to the equivalence of the SST-forced response.

Wu and Kirtman (2004) compared a coupled model simulation with uncoupled simulations forced by an ENSO-related pattern of the SST variability from the coupled simulation, using the Center for Ocean-LandAtmosphere Studies (COLA) CGCM and AGCM. They performed a regression analysis against Indian monsoon rainfall (IMR) index and found that the signs of the regression patterns (e.g., SST outside the index region) were opposite in the AGCM and CGCM. As the regression against remote indices should filter out weather noise, their results indicate that the forced responses of the AGCM and CGCM to the SST forcing are very different.

Kumar et al. (2005) examined the regression of SST against IMR index, using an uncoupled AGCM [National Center for Atmospheric Research (NCAR) Community Climate Model version 3 (CCM3)]. They found that the AGCM forced by observed SST totally disagreed with the observed relationship. However, if the same AGCM was coupled with a mixed layer ocean model except in the tropical Pacific where the observed SST was specified, then the model simulation recovered the observed ENSO-monsoon relationship - that is, wet (dry) IMR corresponding to the cold (warm) SSTs adjacent to northern Indian Ocean and across the ENSO region. Again, since the regression should filter out remote weather noise to the extent that the weather noise is spatially uncorrelated, the results suggest that the forced response might depend on the coupling, although other explanations are also possible, since the SSTs in the uncoupled and partially coupled cases presumably differ outside the tropical Pacific.

Wang et al. (2005) compared a CGCM with an SSTforced AGCM simulation in a perfect model framework, where the SST forcing was the output from the CGCM and the atmospheric component of the CGCM was ECHAM4, the same as the uncoupled AGCM. They examined lag correlations between the local SST and precipitation anomalies and found substantial differences for simultaneous and rainfall-leading correlations between the coupled and uncoupled simulations in a region of the tropical west Pacific. They concluded that the atmosphere-ocean coupling was crucial for seasonal prediction in the Asian-western Pacific summer monsoon region.

Our experiments are designed to exclude the impact of model bias, following the perfect model strategy (e.g., Kitoh and Arakawa 1999; Wu and Kirtman 2004; Wang et al. 2005; Wu et al. 2006; Schneider and Fan 2007). We carry out evaluation of the role of weather noise in climate model simulations in two ways. First, we examine whether the estimated weather noise in the SST-forced AGCM is statistically the same as in the CGCM. Second, we perform the same regression and correlation analyses as in the studies mentioned above ( $\mathrm{Wu}$ and Kirtman 2004; Kumar et al. 2005; Wang et al. 2005; Wu et al. 2006) with "observations" from our perfect model simulations. Our work is part of the Climate Variability and Predictability (CLIVAR) International Climate of the Twentieth Century Project (Folland et al. 2002).

In the following, section 2 describes the models and experiments and introduces the two hypotheses to be tested. The results are presented in section 3, including the tests of the two hypotheses and the discussion of the role of weather noise. Section 4 contains the summary and potential applications.

\section{Models and experiments}

A coupled model and an uncoupled SST-forced atmospheric model are used to carry out the experiments. The experimental design follows the perfect model strategy.

\section{a. The coupled model}

The coupled model (also referred to as the CGCM) is the Community Climate System Model version3 (CCSM3; Collins et al. 2006a) from the National Center for Atmospheric Research. CCSM3 couples the atmosphere, ocean, land, and ice models through a flux coupler without flux correction. The components are the Community Atmosphere Model version 3 (CAM3; Collins et al. 2006b), the Community Land Model version 3 
(Dickinson et al. 2006), the Parallel Ocean Program version 1.4.3 (Danabasoglu et al. 2006), and the Community Sea Ice Model (Holland et al. 2006). The atmospheric model dynamics are spectral with a triangular truncation at total wavenumber 42 (T42) with 26 vertical levels. The transform grid, also used by the atmosphere and land surface physical parameterizations, is 128 longitudinal by 64 latitudinal points. The ocean and ice models have $1^{\circ}$ horizontal resolution and the ocean has 40 vertical levels.

The simulated climate of CCSM3 has some biases. For instance, Deser et al. (2006) showed that CCSM3 had significant mean climate bias in the tropical oceans, in common with most other present-day CGCMs. The ENSO variability in CCSM3 has a shorter-than-realistic and too regular biennial period (e.g., Collins et al. 2006a).

\section{b. The uncoupled model}

The uncoupled atmosphere-land model (also referred to as the AGCM) is the standalone CAM3 (Collins et al. 2006b), the same as the atmospheric component in CCSM3. The version used in this study has the same horizontal and vertical resolutions as in the coupled model. We use the standalone version rather than going through the flux coupler in order to include thermodynamic sea ice. To match the standalone CAM3 with CCSM3, the following settings have been made:

1) Since the ocean-atmosphere coupling frequency is once per day in the CGCM, the AGCM is forced by the daily surface temperature (referred to as TS, same as SST in the ocean grids) and sea ice obtained from the atmospheric model output of the CGCM. A test experiment with the AGCM forced by the monthly boundary conditions from the CGCM output has also been performed, in which we find the TS variance over the ocean is reduced by about $10 \%$ compared to the CGCM output, due to linear interpolation from monthly to daily data. However, TS from the daily data forced AGCM output is perfectly matched with that from the CGCM over the ocean, except in the grid boxes that contain more than one boundary type (ocean plus land and/or sea ice). In these mixed ocean-land-ice grid boxes, TS from the CGCM output is a combination of temperature from the ocean, land, and/or sea ice but is treated as ocean temperature only during forcing the uncoupled AGCM.

2) The topography in the CAM3 is specified as in CCSM3, as the default topography for the standalone CAM3 has some differences from the CCSM3.

3) The external forcing is constant and the orbital year is 1990 in both models.
4) The initial conditions for the AGCM are chosen from an existing CAM3 experiment.

\section{c. Experimental design}

First, the CGCM with constant external forcing is integrated for 100 model years, and is considered as observations. Then an ensemble of six 100-yr AGCM simulations is performed, with each forced by the same boundary condition from the CGCM but starting with different initial atmosphere and surface conditions. Since the atmospheric surface fluxes do not interact with the ocean to change the SST in the AGCM, the surface fluxes in the AGCM ensemble members are different from those in the CGCM.

\section{d. Estimation of weather noise}

Next we describe the determination of the weather noise. An atmospheric variable is composed of two parts. One is the SST-forced response of the atmosphere, taken to be the same for each AGCM ensemble member. The other is the weather noise, which is the internal variability of the atmosphere, and is different for each member. The SST-forced response is obtained as the average of the AGCM ensemble members, so it includes teleconnections from remote SST anomalies and the associated ocean heat storage plus transports can also be inferred. The weather noise in each AGCM ensemble member is defined by subtracting the SST-forced response. Assuming that the SST-forced response is the same in the atmosphere of the coupled and uncoupled models, the weather noise in the CGCM is calculated in the same way: as the value from the CGCM, minus the SST-forced response from the AGCM ensemble mean. This definition of weather noise can be applied to any atmospheric variable.

We use a six-member AGCM ensemble. If the SSTforced response is estimated by the average of all six AGCM members from the ensemble, the weather noise of an AGCM from the ensemble is not independent of the SST-forced response. Therefore, in order to eliminate data dependence, the weather noise of an AGCM ensemble member is calculated by removing the SSTforced response from that member, where the SSTforced response is estimated as the average of the other five ensemble members. Then there are six SST-forced response estimates, leading to six weather-noise estimates for the six AGCMs and also six weather-noise estimates for the CGCM atmosphere. Also, because of the finite size of the AGCM ensemble, errors exist in the estimated SST-forced response and weather noise, and the impact of these errors can be reduced using bias correction. The bias corrections for the SST-forced 
response, the weather noise, the variances, the covariances, and the correlations are derived in the supplemental material, an extension of relationships derived in Rowell et al. (1995), and have been employed in the results shown in the figures.

\section{e. Hypotheses and statistical testing}

The results from the model simulations are used to test two hypotheses:

- Hypothesis 1: The statistics of the weather noise are the same in the AGCM ensemble members and in the CGCM.

- Hypothesis 2: The SST-forced response is the same in the CGCM and each AGCM ensemble member.

We present some simple statistical tests of these hypotheses; however, comprehensive evaluation is outside the scope of this paper. Hypothesis 1 is tested by examining if the standard deviation ratio of the weather noise found in the CGCM to that in the AGCM ensemble members is not significantly different from one. Hypothesis 2 is tested by checking if the regression of a locally defined index onto fields outside the index region is not significantly different in the CGCM and AGCM ensemble members.

\section{Results}

This section tests the hypotheses described above and presents analyses of the role of weather noise. The monthly mean data, with the annual cycle and linear trend removed, are analyzed.

First, the mean climate is examined for both the coupled and uncoupled models. Figure 1a shows that the climatological precipitation is larger in the AGCM than the CGCM over the tropical western and eastern Pacific and northern Indian Ocean, which agrees with Kitoh and Arakawa (1999), and is smaller over the equatorial central Pacific. There are large differences near the ocean-land boundaries in the Maritime Continent, Africa, and East Asia. Most of them disappear when land and mixed grid boxes are masked out (Fig. 1b), which may indicate that the differences near the continents are caused by the differences between the CGCM and AGCM SSTs over the mixed ocean-land grid boxes. These continental precipitation differences could be forcing the precipitation differences over the ocean. Another potential cause for the differences in the precipitation climatologies will be discussed in section $3 \mathrm{a}(6)$.

Since the following results might be affected by different boundary conditions over the mixed grid boxes in the coupled and uncoupled models, we mask the land and mixed grid boxes in subsequent figures.

\section{a. Test of hypothesis 1}

BB98 assumed that the atmospheric weather-noise variances were the same in the coupled and uncoupled models. In this section, we assume the SST-forced response is the same in the CGCM and each AGCM ensemble member, and then examine the standard deviation of both the total fields and the weather noise in the CGCM and AGCM. The $F$ test is used to determine the statistical significance. The degrees of freedom are calculated based on the lag- 1 autocorrelation function (Leith 1973). For instance, the $e$-folding time of the autocorrelation function for air temperature at $850 \mathrm{hPa}$ is around $8-10$ months in the tropical Pacific (not shown), which reduces the degrees of freedom in this region compared to other regions. In the following, the SST-forced component and weather noise of a variable are referred to hereafter as _F and _N, respectively.

\section{1) Net Surface HEAT FluX}

Figure 2 is the standard deviation ratio of the NHF between CGCM and AGCM. Figure 2a shows that the NHF variability is reduced over the ocean in the CGCM simulation compared to the AGCM simulation, consistent with $\mathrm{BB} 98$. The reduction due to atmosphere-ocean coupling is larger in the low-latitude Indian Ocean, tropical western Pacific, and tropical Atlantic, and to the southeast of Australia (more than $20 \%)$ and is smaller in the equatorial central and eastern Pacific, the southern ocean, and near $60^{\circ} \mathrm{N}$ (around 10\%). Figure $2 \mathrm{~b}$ shows that the variance of the NHF_N in the CGCM is the same as that in the AGCM, which supports hypothesis 1 . That is, as in BB98, the NHF_F variance is the same in the coupled and uncoupled simulations, and the NHF_N variance is also the same. However, the total variance is larger in the uncoupled than in the coupled simulations. This occurs because the covariance of NHF_F and NHF_N is negative in the coupled simulation, since the NHF_N is forcing and the NHF_F is damping the SST variability, while NHF_F and NHF_N have no correlation in the uncoupled simulations. Note that it is not completely correct to say that this behavior is the result of the "atmosphere forcing the ocean," as is sometimes stated, since the SST-forced component includes the atmospheric teleconnections from the remote SST anomalies.

Next we diagnose the reasons for these spatial differences. In the regions where the ratio is close to one, the NHF_N is not an important forcing for the SST variability, for example, in the tropical Pacific region. We infer that the model ENSO is not forced by the 


\section{(a) Diff Precip Climatology}

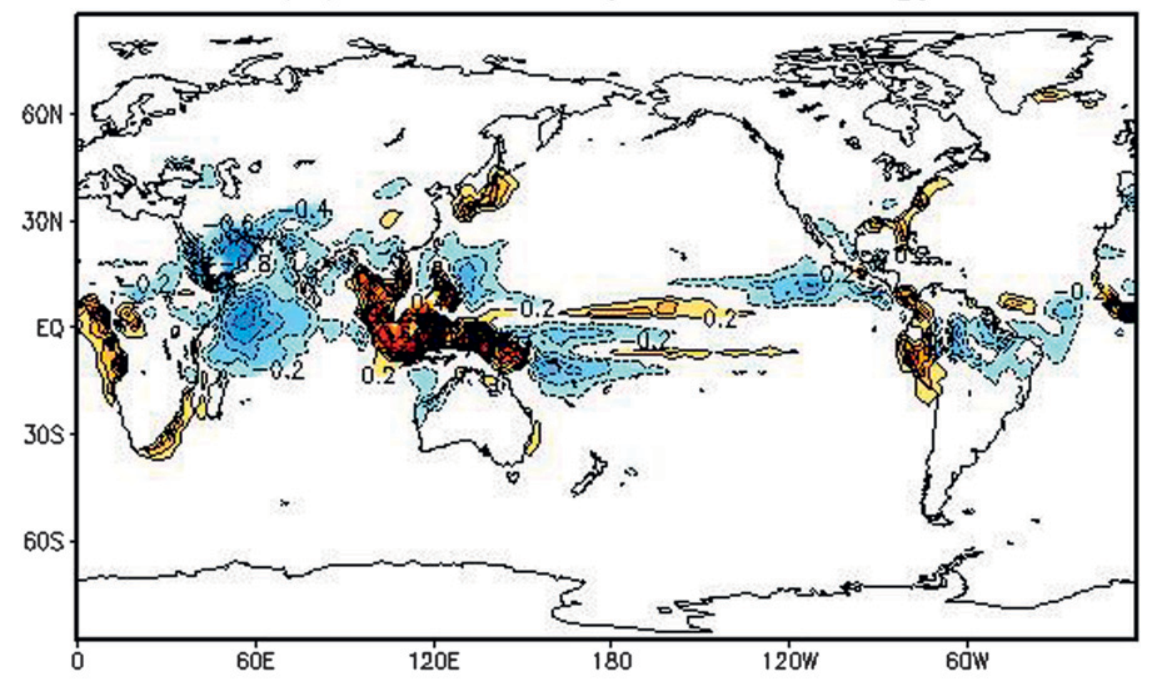

(b) Land Masked

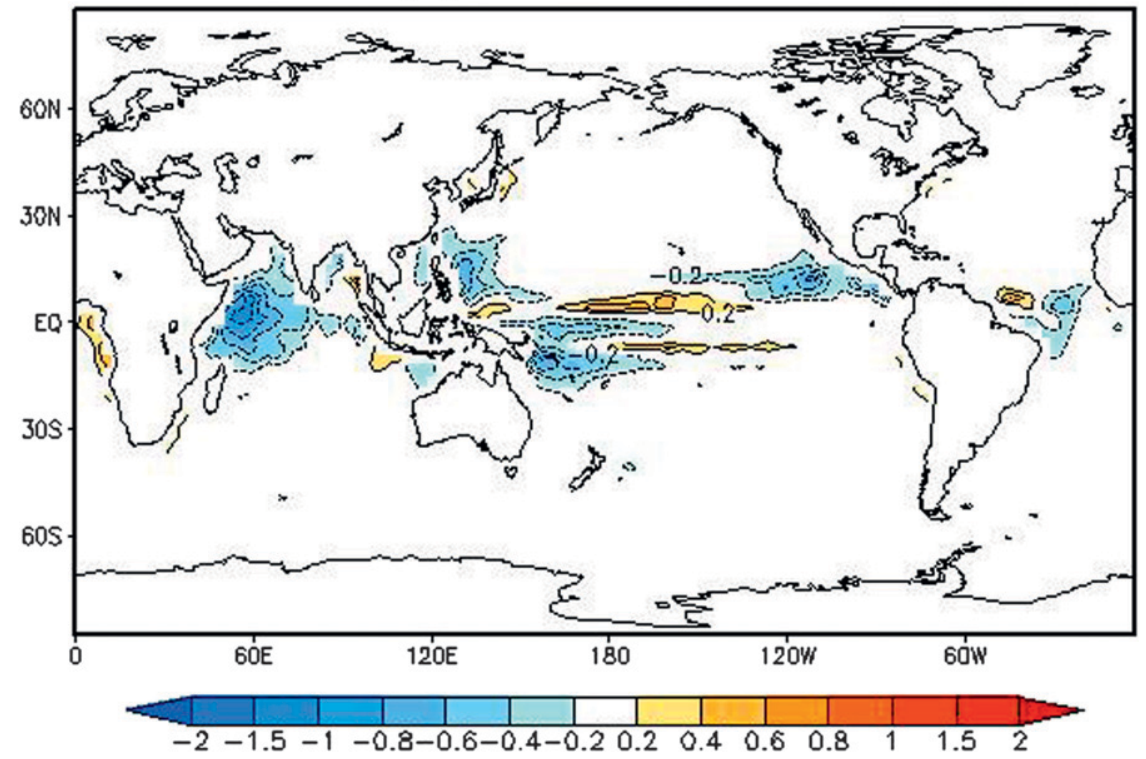

FIG. 1. (a) Differences of climatological precipitation, CGCM minus the average of the six-member AGCM ensemble; (b) as in (a) with masked grid boxes containing land. Unit: mm day ${ }^{-1}$. Values between -0.2 and $0.2 \mathrm{~mm} \mathrm{day}^{-1}$ are not plotted.

NHF_N. This is consistent with the previous result that the model ENSO is an unstable or near-neutral coupled mode in CCSM3 (Kirtman et al. 2009). In the high latitudes of both hemispheres, where the ratio is near one, a reasonable candidate to explain the SST variability is internal ocean dynamics (i.e., ocean "weather noise"; Wu et al. 2004).

The NHF variability is dominated by shortwave radiation (SWR, positive downward) and latent heat flux (LHF, positive upward); thus, the covariance of the
NHF_F and NHF_N, which leads to the CGCM/AGCM variance ratio being different from one, can be expanded into four components [see Eqs. (12) and (13) available as supplemental material at the Journals Online website:http://dx.doi.org/10.1175/JCLID-12-00292.s1]. Figure 3 displays the contributions associated with each of the four terms and their sum. The terms involving the covariances of SWR_F and SWR_N (Fig. 3a) and of SWR_F and LHF_N (Fig. 3b) are both negative in the low-latitude Indian and western Pacific Oceans, with the 


\section{(a) NHF}

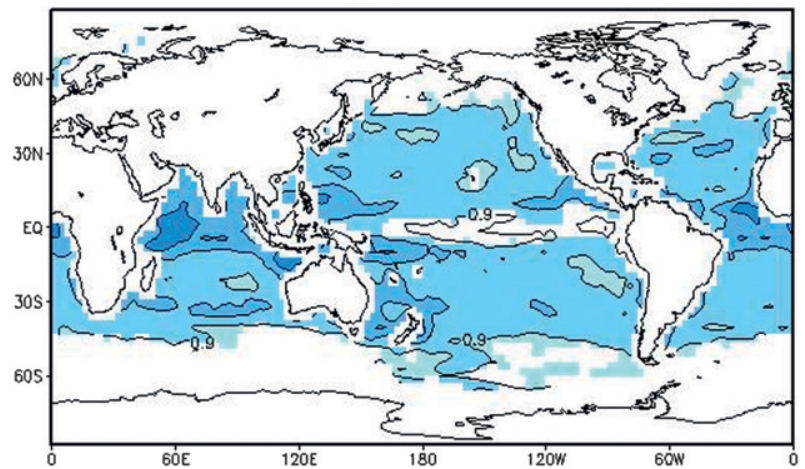

(b) NHF_N

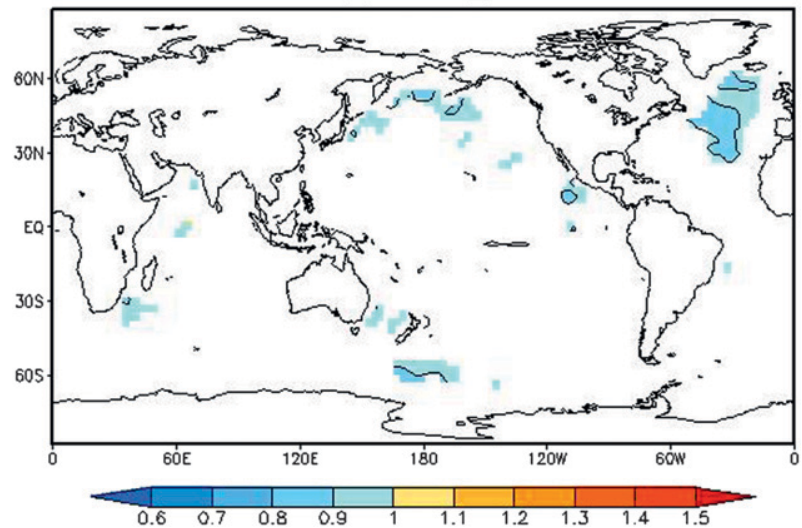

FIG. 2. The bias-corrected standard deviation (STD) ratio (CGCM/AGCM) of (a) net surface heat flux (NHF) and (b) noise NHF. The STD of the NHF in the uncoupled model is represented by the average of six STDs from the six AGCMs. The STD of the noise NHF in the coupled (uncoupled) model is represented by the average of six STDs from six weather-noise estimates in the CGCM (AGCMs) (see text). The colored regions are different from 1 at the $1 \%$ level using the $F$ test. Land and mixed ocean-land/ice grid boxes are masked. The contour interval is 0.1 and the unit contours are not plotted.

former being larger in magnitude, and are both positive in the central and eastern equatorial Pacific, with the latter being larger. The terms involving the covariance with the downward LHF_F (Figs. 3c,d) have less east-west contrast and are predominantly negative in low latitudes. In the western region, both the SWR_F and downward LHF_F correlate negatively with the NHF_N. Thus, the combined contributions to the NHF_N reinforce in the western region, leading to a ratio less than one. However, in the eastern equatorial Pacific, the SWR_F and downward LHF_F correlate with the NHF_N with opposite signs. Therefore, the combined contributions to the NHF_N cancel out in the eastern equatorial Pacific, leading to a ratio closer to one. Figure 3e shows the sum of the four covariance terms. The contribution is negative everywhere in low latitudes (cf. Fig. 2a).

\section{2) SURFACE WIND STRESS AND FRESHWATER FLUX}

Similarly, the standard deviations of the surface wind stress (WS; Fig. 4a) and freshwater flux (FWF; Fig. 4c) in the CGCM are smaller than in the AGCM, although the reductions are not as large as Fig. 2a. Also, similar to Fig. 2b, the standard deviation of the WS_N and FWF_N can be regarded as the same in the CGCM and AGCM except in some small regions (Figs. 4b,d). The mechanisms for the reduction of the WS and FWF variabilities are not as straightforward as that for the NHF. In particular, the mechanisms require connections between WS and SST variabilities (e.g., WS_N forcing SST variability and WS_F damping SST variability), and between FWF and SST variabilities.

\section{3) ATMOSPHERIC TEMPERATURE}

Following the argument of BB98, the NHF serves to damp the air temperature variability. Therefore, reduced NHF variability suggests that the amplitude of the temperature anomalies should increase. This behavior is clearly seen in Fig. 5a, as the standard deviation of air temperature at $850 \mathrm{hPa}$ (referred to as T850) in the CGCM is larger than in the AGCM over the most of extratropical oceans. There is an exception over the central tropical Pacific, where the standard deviation of T850 is smaller in the CGCM than in the AGCM. The variance of T850_N is statistically the same in the CGCM and AGCM except over the same region of central tropical Pacific (Fig. 5b). Thus, hypothesis 1 is supported, except in the central tropical Pacific.

T850 is considered as the free atmospheric temperature, while $2-\mathrm{m}$ air temperature (referred to as $\mathrm{T} 2 \mathrm{~m}$ ) is a purely diagnostic model output field interpolated between the SST and the lowest model level temperature, with a strongly nonlinear interpolation factor that is a function of the surface layer stability, NHF and WS. Figure $5 \mathrm{e}$ shows that the standard deviation ratio of $\mathrm{T} 2 \mathrm{~m}$ in the CGCM is larger than in the AGCM over most of the extratropical oceans and is smaller over the tropical oceans, but the spatial structure is not the same as the T850 (Fig. 5a). However, the T2m_N (Fig. 5f) is greater than one for most of the global oceans. Thus, hypothesis 1 is rejected for this field. It is not clear to us why $\mathrm{T} 2 \mathrm{~m}$ differs from other fields in the weather-noise ratio.

\section{4) SEA LEVEL PRESSURE}

The difference of sea level pressure (SLP) variability is less than $10 \%$ between the coupled and uncoupled models (Fig. 5c). The difference in the midtroposphere, such as the $500-\mathrm{hPa}$ geopotential height variability, is 
(a) $\operatorname{Cov}($ SWR_F,SWR_N)

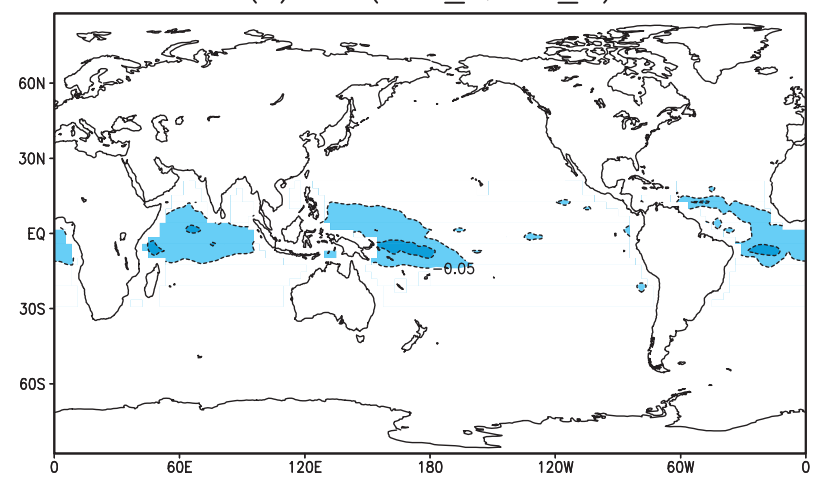

(c) $\operatorname{Cov}($ SWR_N, -LHF_F)

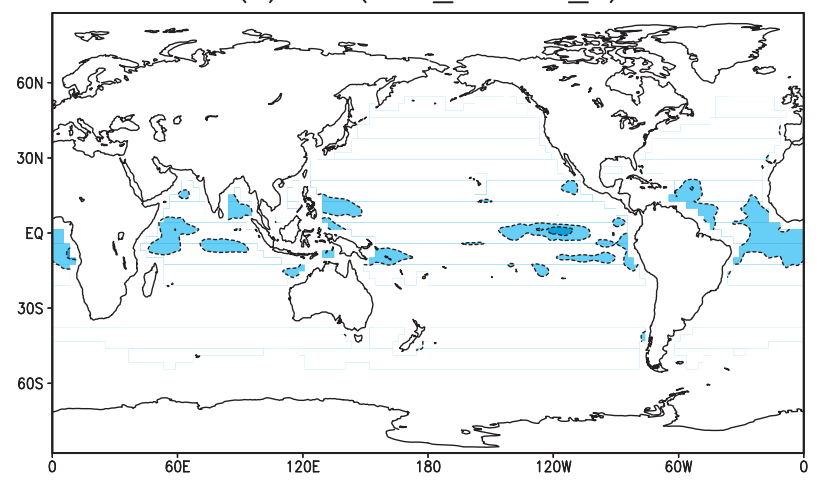

(b) $\operatorname{Cov}\left(S W R \_F,-L H F \_N\right)$

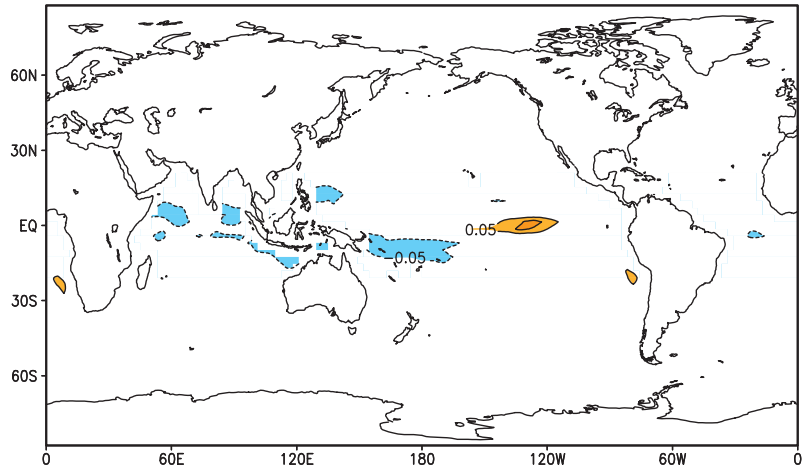

(d) $\operatorname{Cov}\left(-L H F \_F,-L H F \_N\right)$

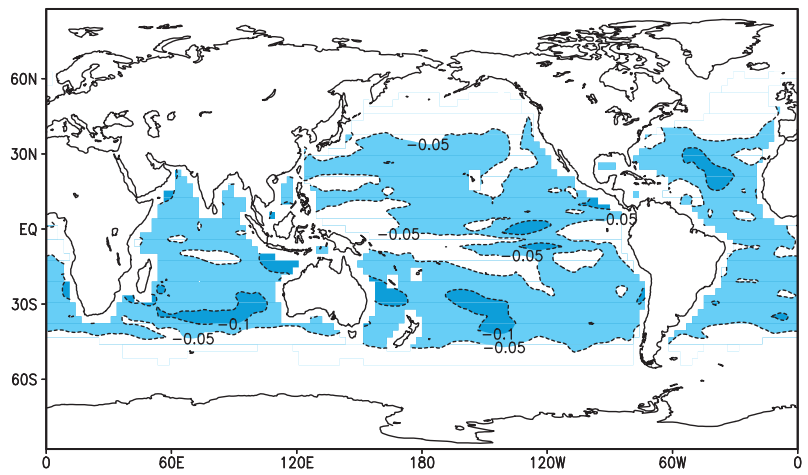

(e) Sum

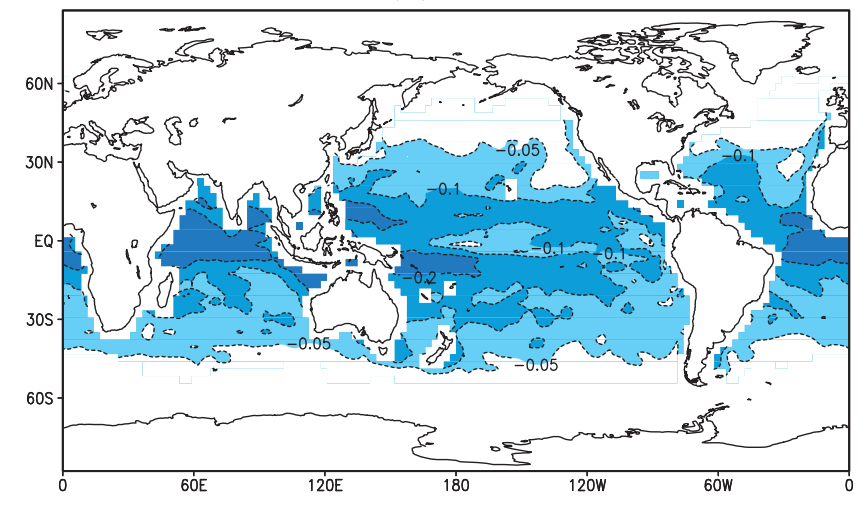

\begin{tabular}{lll|ll|l|l|l|l|l|l|}
\hline & & & & & & & & & & \\
-0.6 & -0.4 & -0.2 & -0.1 & -0.05 & 0.05 & 0.1 & 0.2 & 0.4 & 0.6
\end{tabular}

FIG. 3. The bias-corrected covariances from the CGCM of (a) forced shortwave radiation (SWR) and noise SWR, (b) forced SWR and $-1 \times$ noise latent heat flux $(\mathrm{LHF}),(\mathrm{c})$ noise SWR and $-1 \times$ forced LHF, and $(\mathrm{d})-1 \times$ forced LHF and $-1 \times$ noise LHF. The covariances are divided by the variance of the net surface heat flux from the AGCM. (e) The sum of (a)-(d). Values between -0.05 and 0.05 are not plotted. 
(a) WS

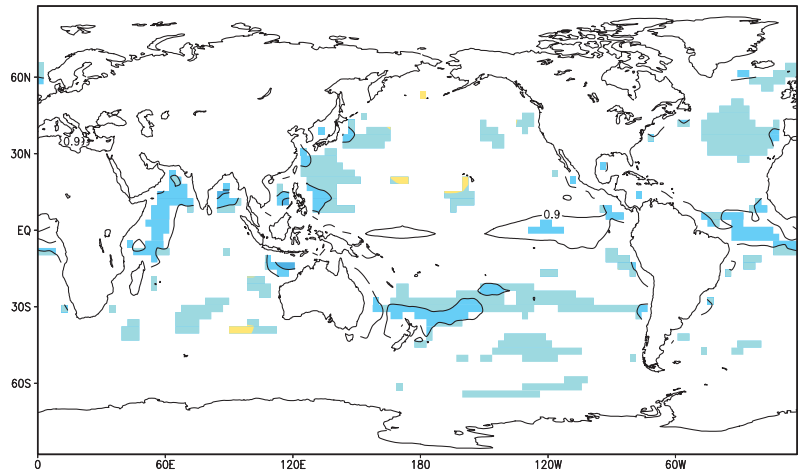

(c) FWF

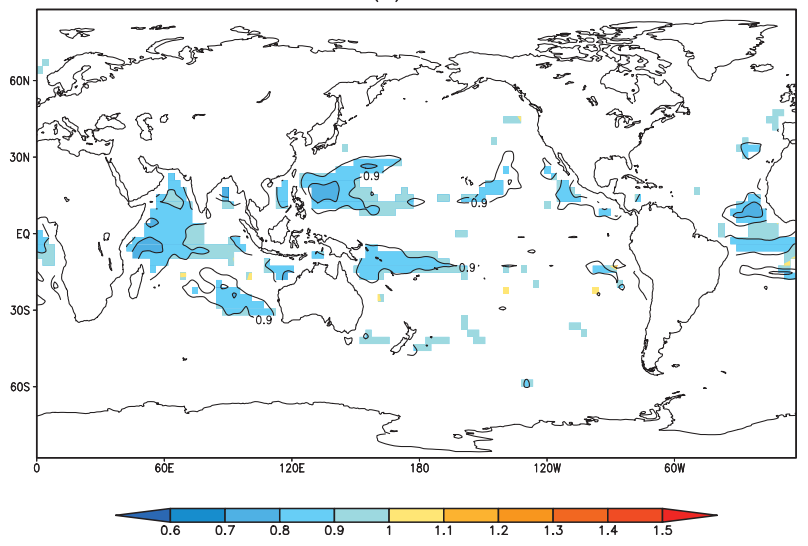

(b) WS N

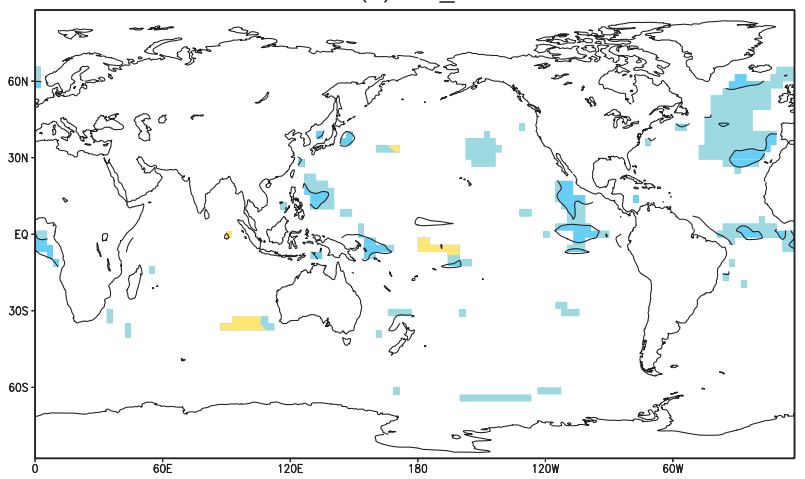

(d) FWF_N

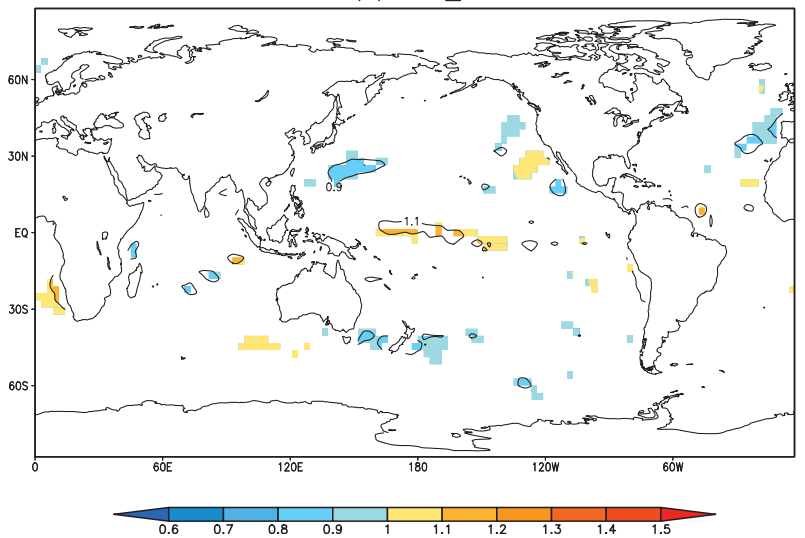

FIG. 4. As in Fig. 2, but for (a) surface wind stress (WS), (b) noise WS, (c) freshwater flux (FWF), and (d) noise FWF.

even smaller (not shown). The CGCM/AGCM ratio of SLP_N is not different from one, except for some relatively small areas in the eastern North Atlantic and eastern North Pacific, and in the Southern Ocean to the south of Australia (Fig. 5d).

\section{5) Precipitation}

A pronounced reduction of precipitation variability in the coupled model occurs over much of the tropics (Fig. 6a). The CGCM/AGCM weather-noise ratio is not significantly different from one over most oceans, except for small regions in the equatorial central Pacific, the eastern and western North Pacific, the eastern North Atlantic, and the southern Indian Ocean (Fig. 6b). The reduction of the total precipitation is again due to interference between the SST-forced and weather-noise precipitation variability. The NHF variability in our results is dominated by LHF and SWR, and reduced NHF variability corresponds to reduced LHF variability (as in $\mathrm{Wu}$ et al. 2007). The reduced LHF variability could then cause the reduced precipitation variability.
The spatial structure of the coupled to uncoupled precipitation ratio in low latitudes (Fig. 6a) has substantial spatial variability. The conceptual model for the noise forcing and the SST-forced response to covary is 1) the noise forces the SST, and 2) there is a substantial response to the SST, so that the SST-forced response is then related to the noise. To understand the precipitation-SST connection, we then need to examine the mechanisms by which noise precipitation forces SST anomalies and SST anomalies force precipitation anomalies. Since it is not the precipitation directly but rather the NHF and heat flux divergence due to ocean dynamics that cause the SST to vary, we additionally examine the relationship between the noise precipitation and the NHF_N. The structure of the pattern could also involve WS_N and ocean dynamics, but we do not examine that possibility here.

Relationships between the noise precipitation and NHF_N are displayed in Fig. 7. In the tropics, the regions of higher precipitation in the uncoupled model (Fig. 6a) generally coincide with regions of larger 
(a) 1850

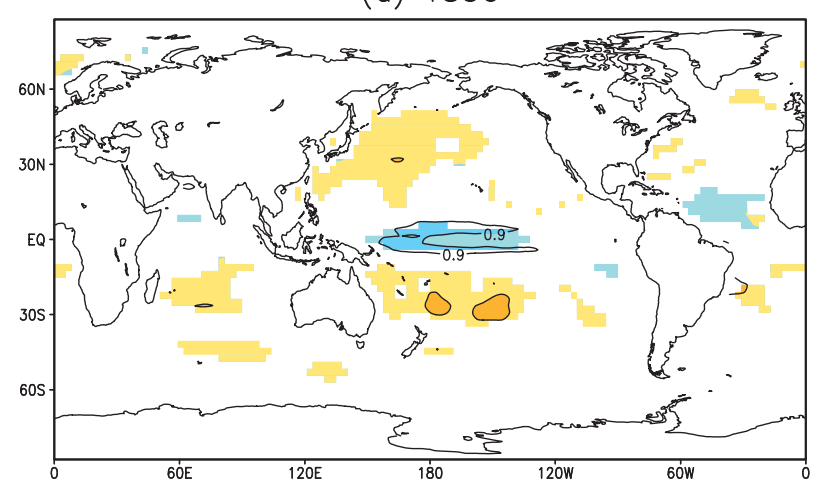

(c) SLP

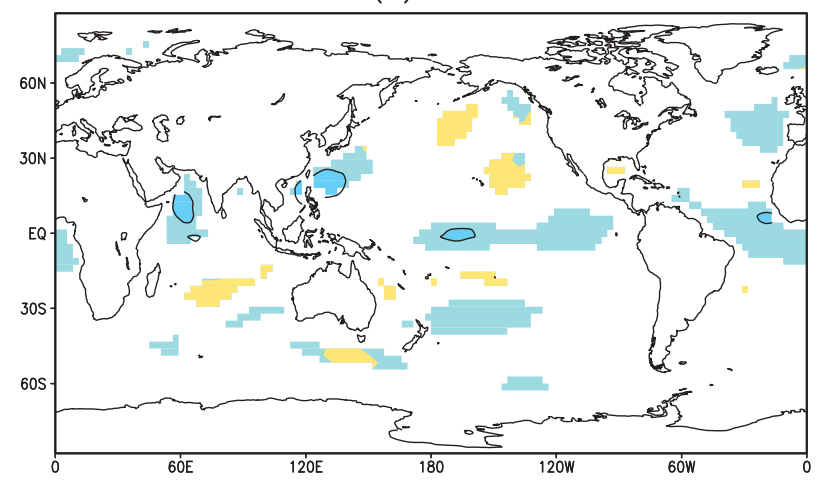

(e) $\mathrm{T} 2 \mathrm{~m}$
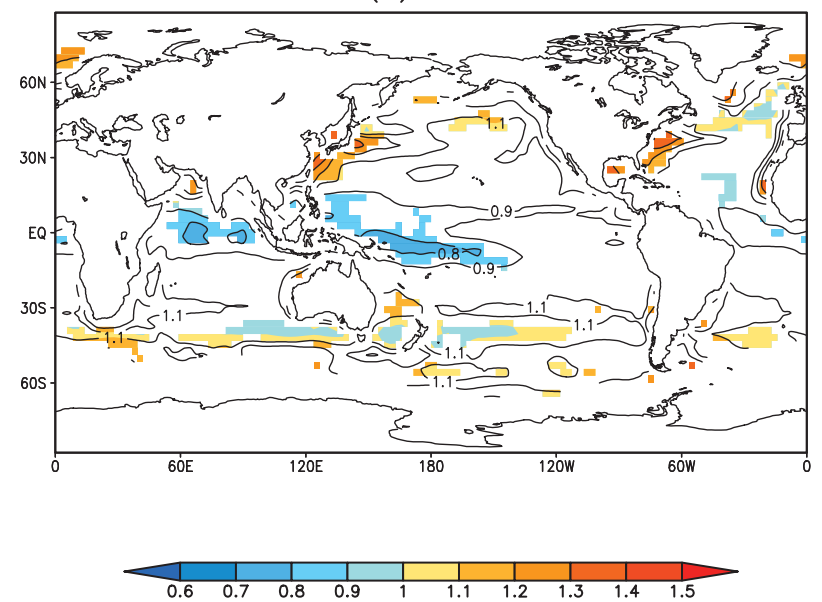

(b) T850_N

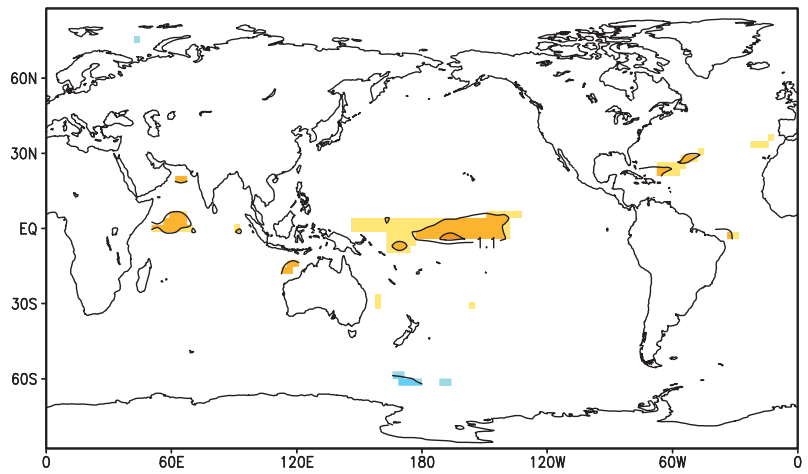

(d) SLP_N

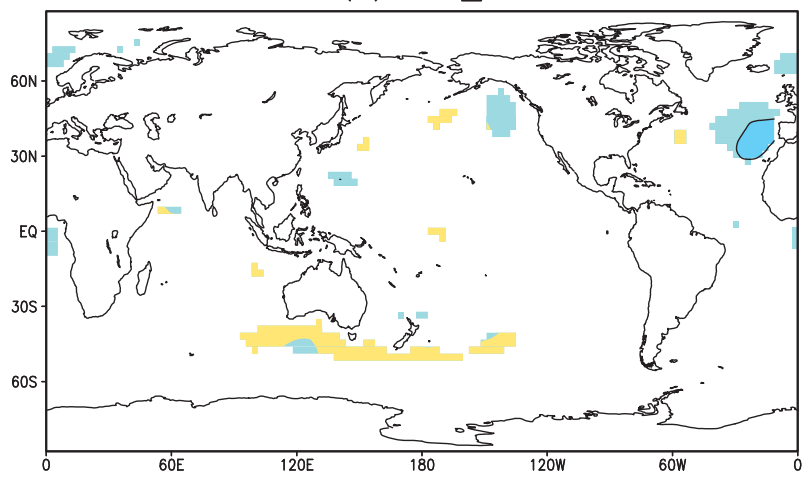

(f) T2m_N
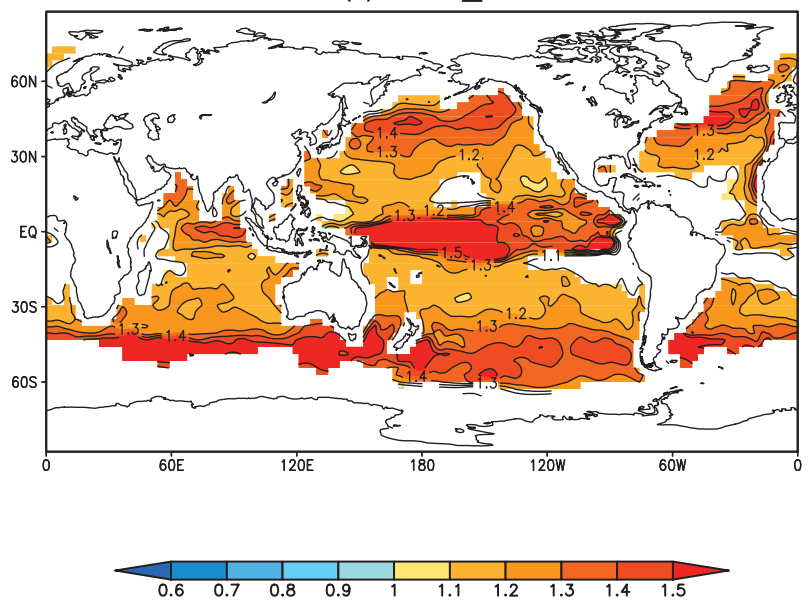

FIG. 5. As in Fig. 2, but for (a) air temperature at $850 \mathrm{hPa}$ (T850), (b) noise T850, (c) sea level pressure (SLP), (d) noise SLP, (e) 2-m air temperature $(\mathrm{T} 2 \mathrm{~m})$, and (f) noise $\mathrm{T} 2 \mathrm{~m}$. 
(a) Precip

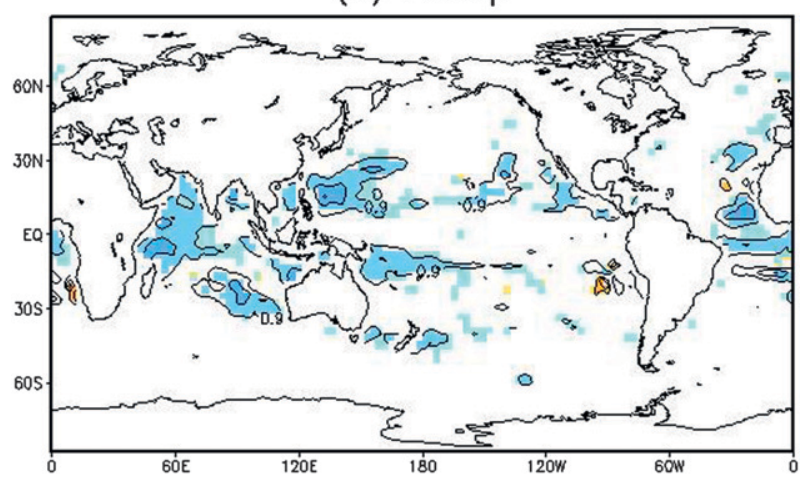

(b) Precip_N

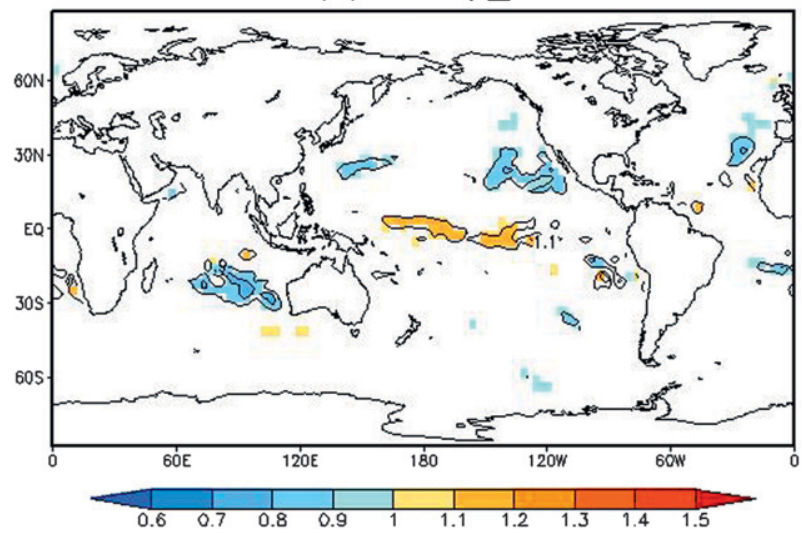

FIG. 6. As in Fig. 2, but for (a) precipitation and (b) weather-noise precipitation.

negative correlation of NHF_N with noise precipitation (Fig. 7a). The SWR_N is negatively correlated with noise precipitation everywhere (Fig. 7c), as might be expected since precipitating clouds shade and cool the surface. The correlation of the downward LHF_N with noise precipitation has a banded structure, with altering zonal bands of positive and negative correlations (Fig. 7b). The regions where the LHF_N and SWR_N effects have the same sign seem to coincide with the regions of enhanced precipitation in the uncoupled model. We infer that it is in these regions that the noise precipitation is most efficient in forcing SST anomalies, and the atmosphere and ocean are most closely coupled.

\section{6) Climatological Precipitation DIFFERENCES}

The regions of enhanced precipitation in the AGCM (Fig. 6a) also appear to coincide with regions where the climatological precipitation in the AGCM is larger than in the CGCM (Fig. 1b). Since the precipitation in these areas appears to be primarily weather-noise forced and episodic, we speculate that the differences in the climatology are a real effect rather than due to

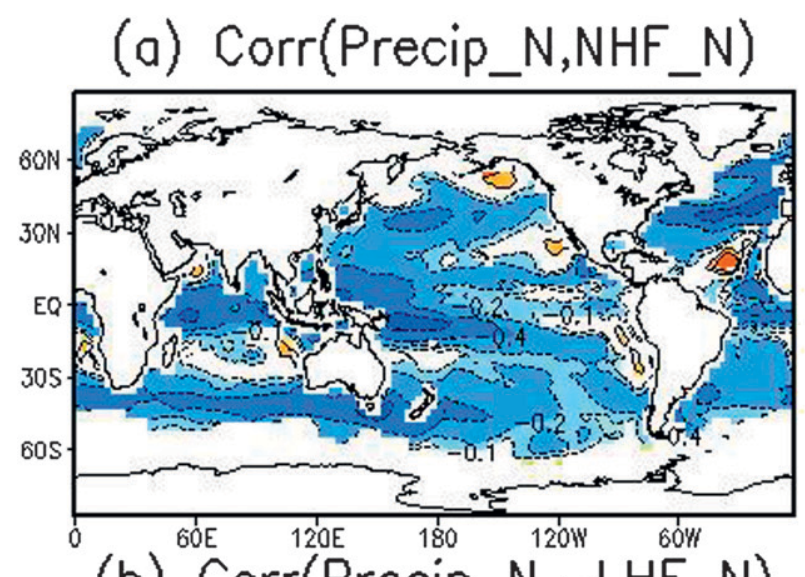

(b) Corr(Precip_N,-LHF_N)
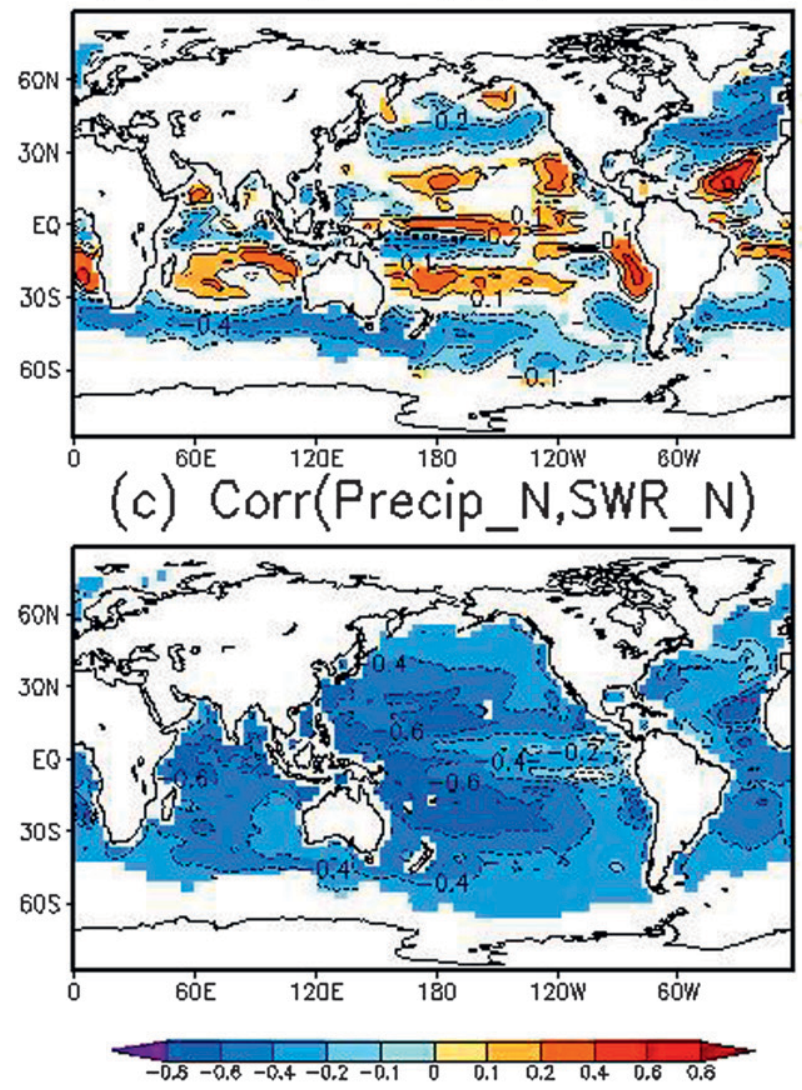

FIG. 7. Pointwise bias-corrected correlations from the CGCM (a) between noise precipitation and noise net heat flux, (b) between noise precipitation and $-1 \times$ noise latent heat flux, and (c) between noise precipitation and noise shortwave radiation. The colored regions are statistically significant at the $5 \%$ level using the $t$ test. The zero contours are not plotted.

one of the flaws in the experimental design, and occur because total precipitation is nonnegative. The probability distribution function of precipitation in this case is not a normal distribution, but is rather more like a Maxwell-Boltzmann distribution. The mean precipitation and the variance are then not independent-in order for 
the width of the distribution to increase, the mean also must increase. The smaller precipitation variability in the CGCM, due to coupling, would then be associated with reduced mean precipitation compared to the AGCM.

\section{7) SuMMARY OF TEST OF HYPOTHESIS 1}

The above results are robust among the AGCM ensemble members. Coupling generally reduces the variances of the surface fluxes and the thermal damping effect. Hence, the air temperature variance is enhanced over the extratropics, but the effects are small $(<10 \%)$ over most oceanic regions. The weather noise in the CGCM atmosphere generally is statistically the same as the AGCM atmosphere, although not everywhere, supporting hypothesis 1 .

\section{b. Test of hypothesis 2}

Hypothesis 2, that the forced response is the same in the coupled and uncoupled models, is necessary to be true for our weather noise calculation to be valid. We devise a test for this hypothesis independent of the weather noise calculation, based on the assumption that the weather noise is spatially uncorrelated at sufficiently large horizontal scales. Then regression of a locally defined index onto fields elsewhere will isolate the forced response for regions sufficiently distant from the index region. We also check the assumption of spatial independence of the noise for consistency with the regression results by verifying that the weather noise calculated as in section 3a is uncorrelated or correlated with the noise in the index. As an example, the test is applied with respect to an IMR index, defined below, as several investigators have considered regressions against this index with different models. In future research we plan to compare the coupled and uncoupled forced responses more comprehensively.

$\mathrm{Wu}$ and Kirtman (2004) found that the negative correlation between an IMR index and ENSO in the COLA IE CGCM was reversed when the COLA AGCM was forced by a dominant SST pattern extracted from a simulation made with the COLA IE CGCM. This behavior fails our test and implies that in the COLA model either the forced response in the CGCM is different from that in the AGCM, or the weather noise is spatially correlated. Figure 8 (plotted for comparison with Figs. 3 and 7 a from Wu and Kirtman 2004) shows June-September (JJAS) mean precipitation, LHF, and SST anomalies derived from regression with an IMR index from our simulations for the CGCM and a single AGCM ensemble member. The index is defined as the average of summer precipitation over the region of $5^{\circ}-25^{\circ} \mathrm{N}, 60^{\circ}-100^{\circ} \mathrm{E}$.

The most striking feature of Fig. 8 is that the AGCM simulates the same monsoon-ENSO relationship as the CGCM to a very high degree. Specifically, the precipitation anomalies (Figs. 8a,b) are positive over the northern Indian Ocean and negative over the equatorial central and eastern Pacific. The LHF (Figs. 8c,d) corresponds well to the precipitation, with positive anomalies over the northern and southern Indian Ocean and negative anomalies over the equatorial eastern Pacific. The positive area over the northern Indian Ocean is insignificant in the coupled model but significant in the uncoupled model at the $10 \%$ level. The major difference occurs close to the index region and will be analyzed below. Increased IMR is associated with warmer SST in the northern Indian Ocean and cooler SST in the equatorial central and eastern Pacific (Figs. 8e,f). In sum, outside of the immediate vicinity of the index region, the uncoupled model is able to reproduce the relationship between the IMR and ENSO of the coupled model, and the relationship that we find is opposite to that of Wu and Kirtman (2004). We have verified that the weather noise in the regions where the regression is the same is uncorrelated with the weather noise in the index. Therefore, the forced response is the same in CCSM3 and CAM3, except close to the index region, supporting hypothesis 2 for these models. The good agreement of Figs. 8e and $8 \mathrm{f}$ implies that the discrepancies between observations and AGCM simulations in Kumar et al. (2005), which used the same model as we do, would seem to be attributable to model bias rather than specifying SST in the AGCM.

To try to understand the cause for the difference between our results and those described by $\mathrm{Wu}$ and Kirtman (2004), we also analyzed the results from a set of perfect model coupled versus uncoupled simulations described in Schneider and Fan (2007), which employed the same COLA AGCM as Wu and Kirtman (2004) but used the standard COLA CGCM, instead of COLA IE CGCM, to perform the coupled simulation. We found that the uncoupled model could simulate the monsoonENSO relationship of the coupled model in the western Pacific, but not in the eastern Pacific (not shown). Therefore, the properties of the COLA model are different from those of CCSM3, and there is model dependence in the consistency of the regression relationship.

Now we look at the difference of the LHF regressions over the northern Indian Ocean, $\sim(4-6) \mathrm{W} \mathrm{m}^{-2}$ smaller in the CGCM than in the AGCM (Figs. 8c,d). To investigate, we decompose an atmospheric variable into SST-forced and weather-noise parts, and expand the covariance of the total IMR index and total LHF (Figs. 9a,b) into four terms, and then compare each term from the coupled model to the one in the uncoupled model. The forced-forced covariance (Figs. 9c,d) is the same in both models from the assumption of hypothesis 
(a) Precip
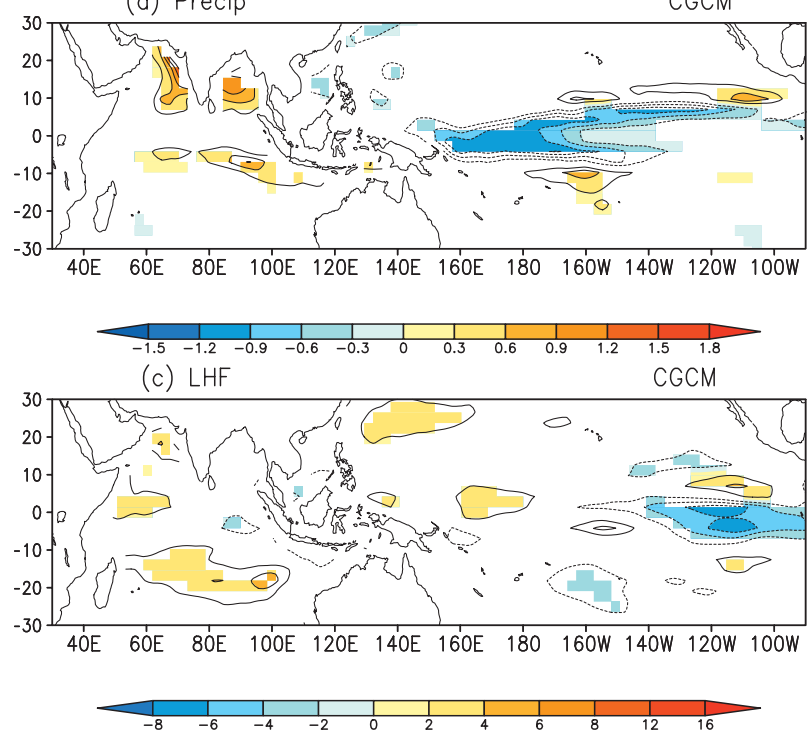

(e) SST

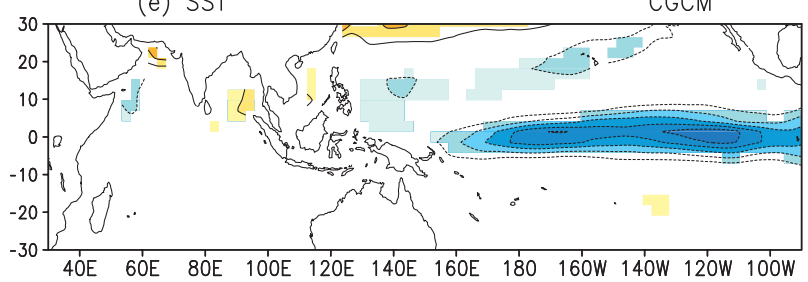

(b) AGCM

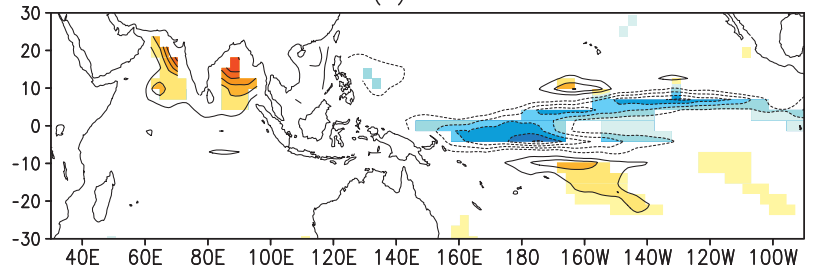

(d) AGCM
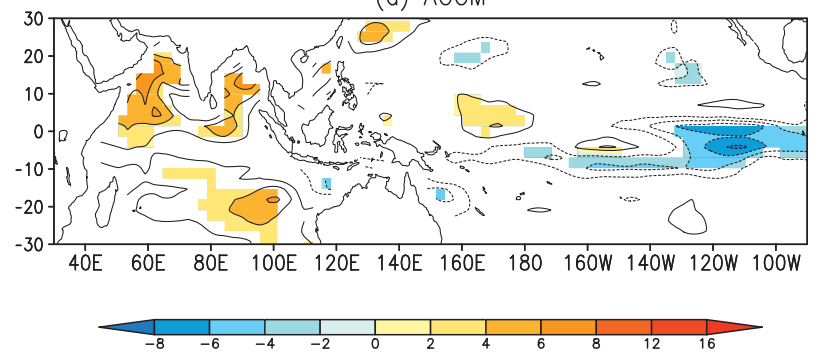

(f) AGCM
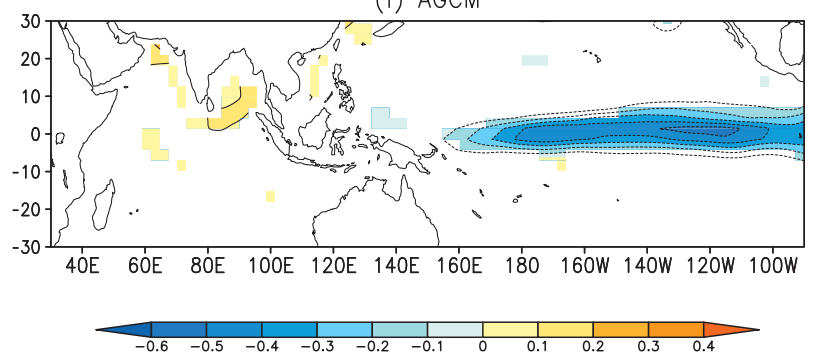

FIG. 8. June-September (JJAS) mean (a),(b) precipitation, (c),(d) latent heat flux, and (e),(f) SST anomalies, derived from regression with normalized JJAS Indian monsoon rainfall index (the average of summer rainfall over the region of $\left.5^{\circ}-25^{\circ} \mathrm{N}, 60^{\circ}-100^{\circ} \mathrm{E}\right)$ from $(\mathrm{left}$ ) the CGCM and (right) a single AGCM ensemble member. The contour interval is $0.3 \mathrm{~mm}$ day ${ }^{-1}$ for precipitation, $2 \mathrm{~W} \mathrm{~m}{ }^{-2}$ for latent heat flux, and $0.1^{\circ} \mathrm{C}$ for SST. The zero contours are not plotted. The colored regions are statistically significant at the $10 \%$ level using the $t$ test.

1, and the noise-noise covariance (Figs. 9i,j) is rather small in both models. The forced-noise and noise-forced covariances are different, particularly close to the index region. In the CGCM, the IMR_F (IMR_N) is negatively correlated with the LHF_N (LHF_F) in the region where the rainfall index is defined (Figs. 9e,g), while they are not related in the SST-forced AGCM (Figs. 9f,h). Note that there are some anomalies over the tropical Pacific in the CGCM (Figs. 9e,g,i), which might be residuals not completely removed by bias correction. The weather noise affects the SST-forced response only close to the index region. Thus, the result that Figs. 9a and 9b differ only in the index region is due to the local negative correlation between SST-forced response and the weather noise in the coupled model, compared to zero correlation in the uncoupled model.

\section{c. Role of weather noise}

The role of weather noise has been mentioned above with regard to testing the two hypotheses. In the following, we further examine it through comparison of the local correlations with SST and SST tendency.

\section{1) LOCAL SST-PRECIPITATION CORRELATION IN THE ASIAN SUMMER MONSOON REGION}

In a perfect AMIP experiment using the ECHAM model described in Wang et al. (2005), the AGCM failed to simulate the simultaneous negative SSTprecipitation correlation of the CGCM during JJAS in the Asian-western Pacific summer monsoon region (oceans in the box region in Fig. 10). Since this is a local result, weather noise is not filtered out by the correlations.

Our version of this result using CCSM3 is shown for simultaneous correlations in Fig. 10, and is similar to that found by Wang et al. (2005). The pointwise correlation between the monthly SST and precipitation anomalies from June to September is insignificant at the $5 \%$ level (though positive) in the box region in the CGCM (Fig. 10a) and positive in the AGCM (Fig. 10b). 
(a) (IMR_T,LHF_T)

CGCM

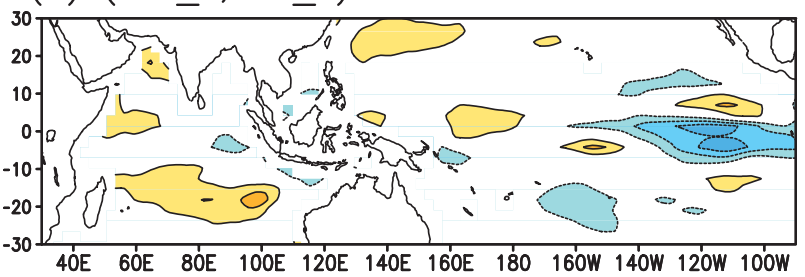

(c) (IMR_F,LHF_F)

CGCM

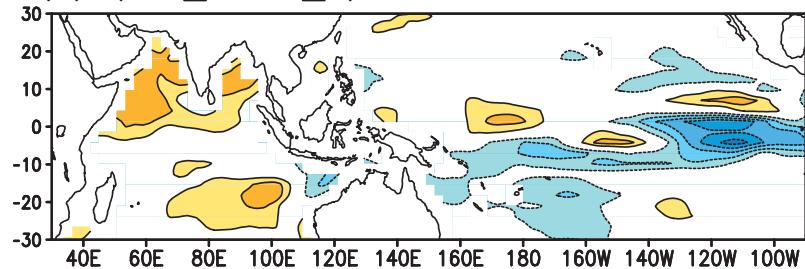

(e) (IMR_F,LHF_N)

CGCM

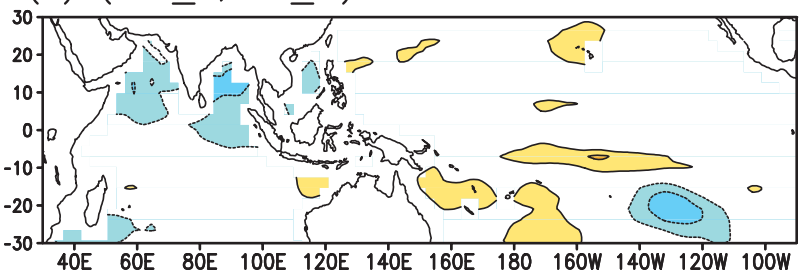

(g) (IMR_N,LHF_F)

CGCM

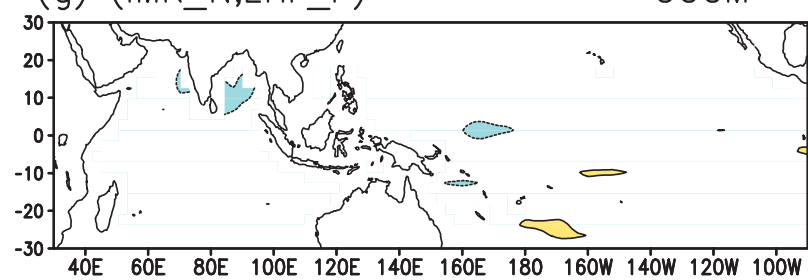

(i) (IMR_N,LHF_N)

CGCM

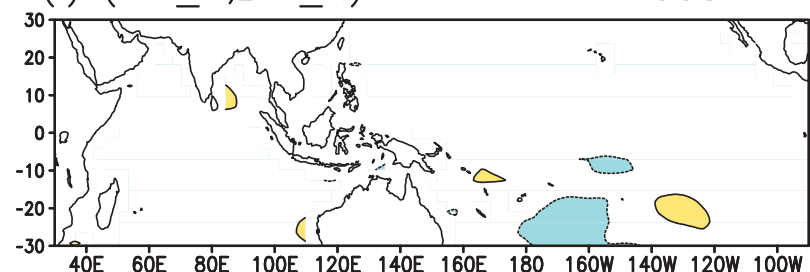

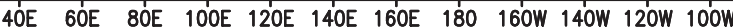

(b) AGCM

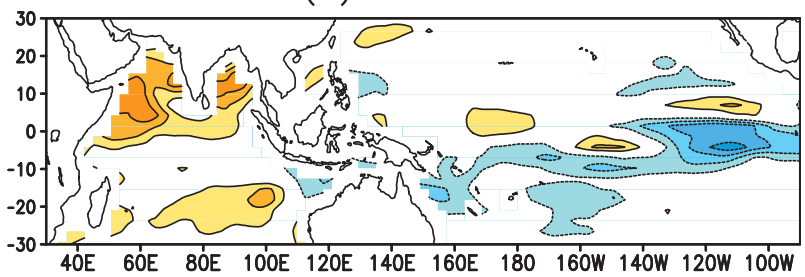

(d) AGCM

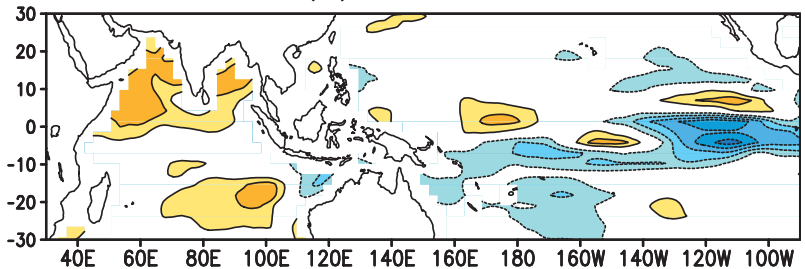

(f) AGCM

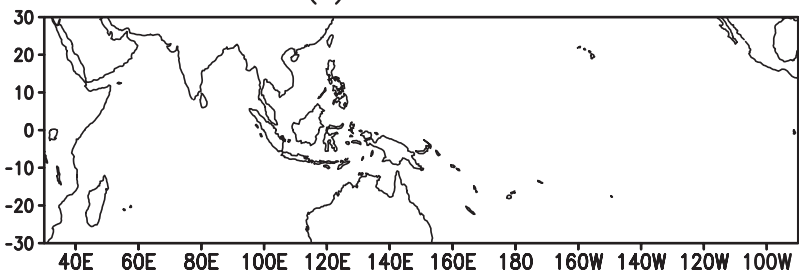

(h) AGCM

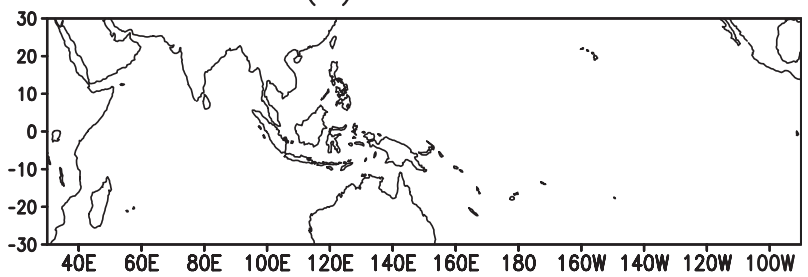

(j) AGCM

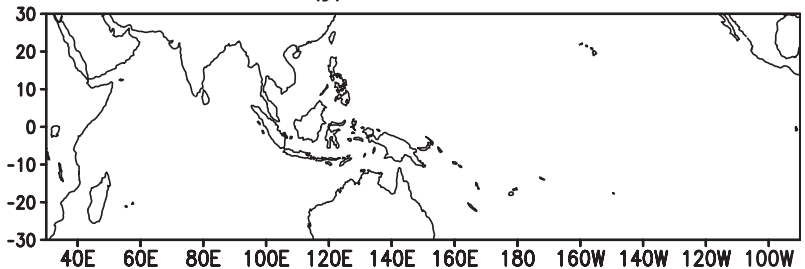

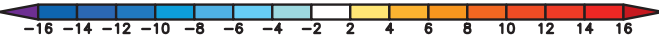

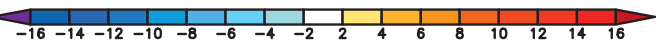

FIG. 9. Bias-corrected covariance of the JJAS Indian monsoon rainfall (IMR) index and latent heat flux (LHF) from the (left) CGCM and (right) AGCM. Shown are covariances of (a),(b) the total field, (c),(d) the forced IMR and forced LHF, (e),(f) the forced IMR and noise LHF, (g),(h) the noise IMR and forced LHF, and (i),(j) the noise IMR and noise LHF. Note that (b),(d),(f),(h), and (j) are represented respectively by the average of six covariances from six AGCMs, while (c),(e),(g), and (i) are represented respectively by the average of six covariances from the CGCM, with six atmospheric weather-noise components in the CGCM corresponding to six SSTforced components (see section $2 \mathrm{~d}$ ). The contour interval is $2 \mathrm{~W} \mathrm{~m}^{-2}$ and values between -2 and $2 \mathrm{~W} \mathrm{~m}^{-2}$ are not plotted. 
(a) $\operatorname{Cor}($ SST,Precip) CGCM

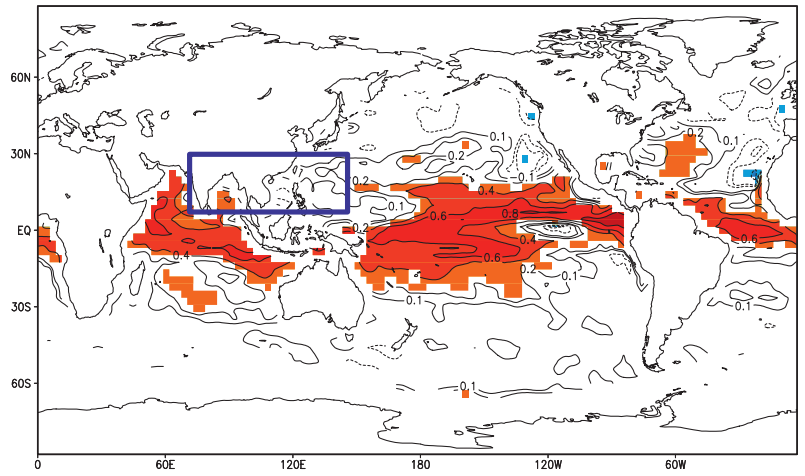

(c) (a) minus (b)

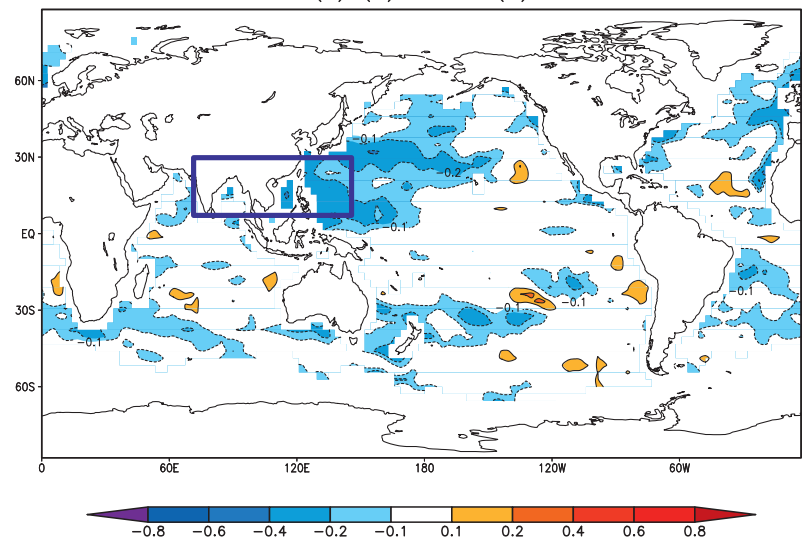

(b) $\operatorname{Corr}($ SST,Precip) AGCM

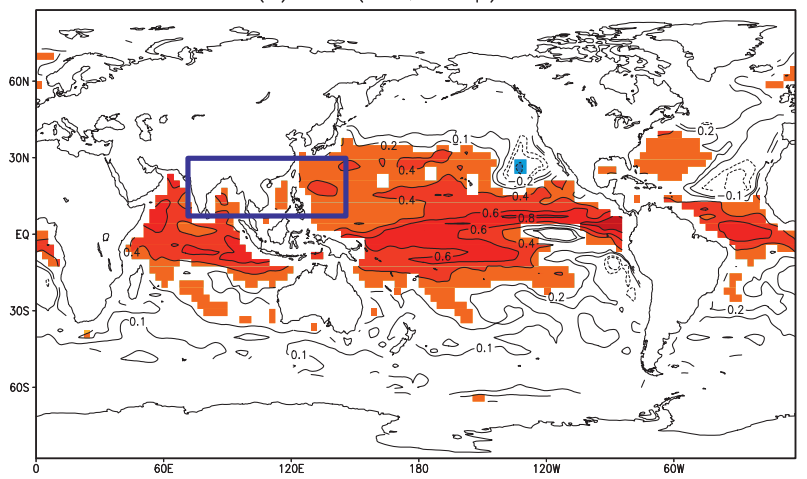

(d) Corr(SST,Precip_N) CGCM

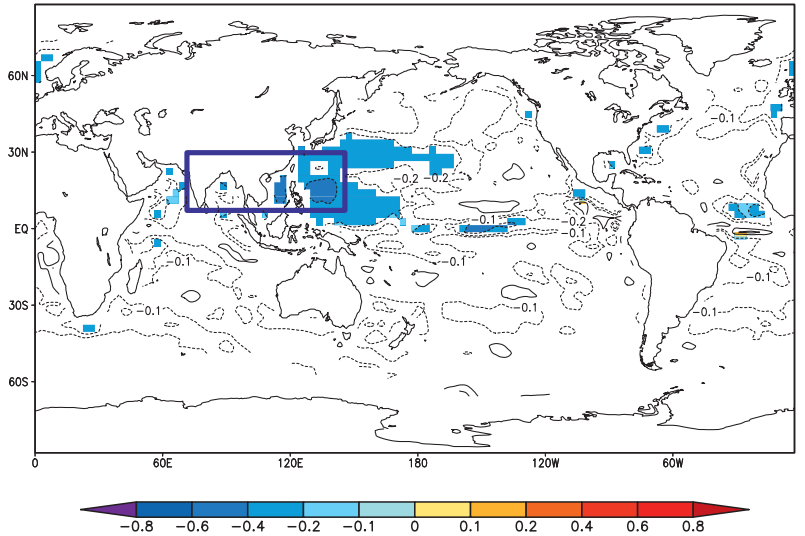

FIG. 10. Simultaneous pointwise correlations between the monthly SST and precipitation anomalies computed for JJAS in the (a) CGCM and (b) AGCM. All the colored regions are statistically significant at the 5\% level using the $t$ test. The bold blue box shows the Asian-western Pacific summer monsoon region. (c) Difference of (a) and (b). Values between -0.1 and 0.1 are not plotted. (d) Biascorrected pointwise correlation between the monthly SST and weather-noise precipitation in the CGCM. All the colored regions are statistically significant at the $5 \%$ level using the $t$ test. The same color bar is used for (a),(b), and (d); (c) has its own bar.

The AGCM result indicates that positive SST anomalies force the positive precipitation anomalies. Figure 10c shows that the correlation in the CGCM is smaller than that in the AGCM in regions including the box region, the northwest Pacific, and other oceans; thus, the box region does not appear to be particularly special in this measure. The difference of the correlation [given by Eq. (16) in the supplemental material] is found to be determined by the correlation between the noise precipitation and SST in the CGCM. This correlation is zero in the AGCM. Figure 10d shows the noise precipitationSST correlation in the CGCM, which is in agreement with Fig. 10c in the large negative regions in the box and northwest Pacific. The differences of the SSTprecipitation correlation between CGCM and AGCM simulations are caused by the precipitation-related local weather-noise forcing of SST in the CGCM. The difference between the CGCM and AGCM relationships is then not in the response of the precipitation to the SST, which can be consistently viewed as the same in the coupled and uncoupled models, nor in the statistics of the noise precipitation, which can be consistently argued to be the same in the coupled and uncoupled models, but rather in the temporal relationship between the noise precipitation and SST variability.

We note that Fig. 10d shows that the noise precipitation variability is negatively correlated with SST over many of the regions where the AGCM precipitation variance is enhanced in Fig. 6a, especially north of the equator. The low correlations in the box region in Fig. 10a are evidence that precipitation-related weather-noise forcing of SST is dominant. This could have practical implications for understanding the predictability of the Asian-western Pacific summer monsoon. 
(a) $\operatorname{Corr}(\mathrm{LHF}, \mathrm{SST})$ CGCM

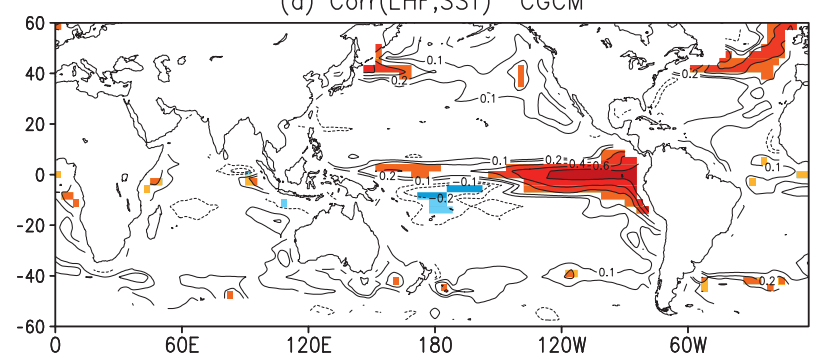

(b) $\operatorname{Corr}(\mathrm{LHF}, \mathrm{SST})$ AGCM

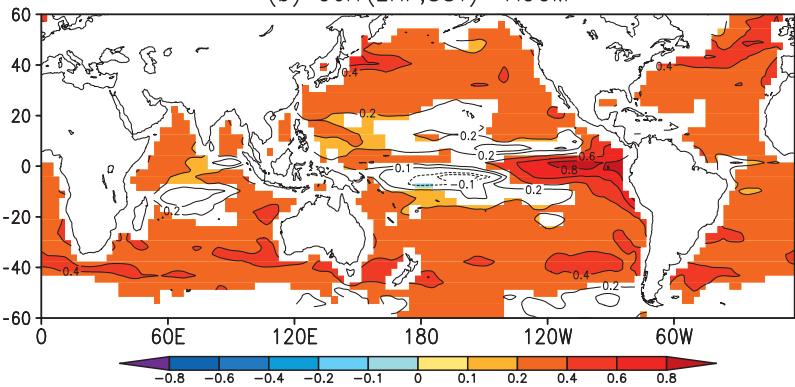

(c) (a) minus (b)

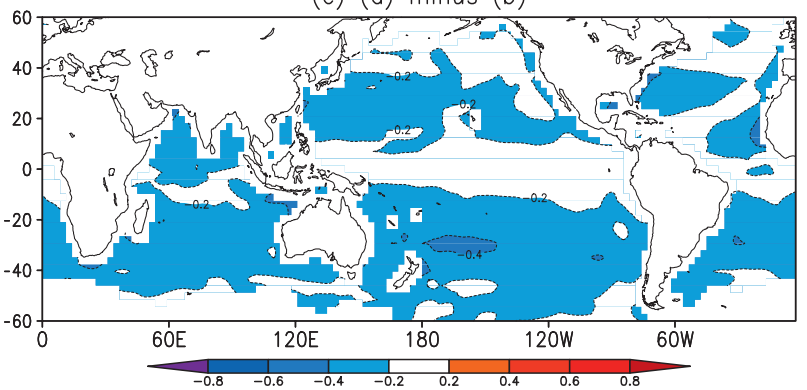

(d) $\operatorname{Corr}($ LHF,SST tend) CGCM

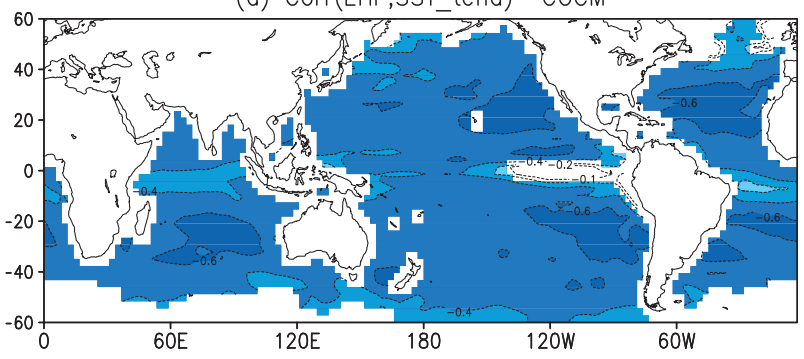

(e) Corr(LHF,SST_tend) AGCM

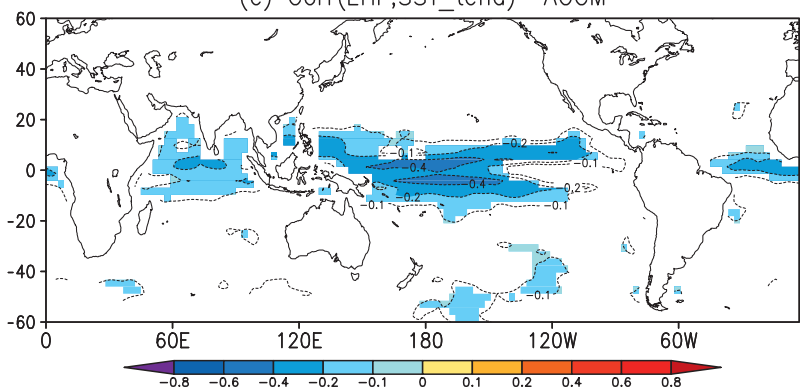

(f) (d) minus (e)

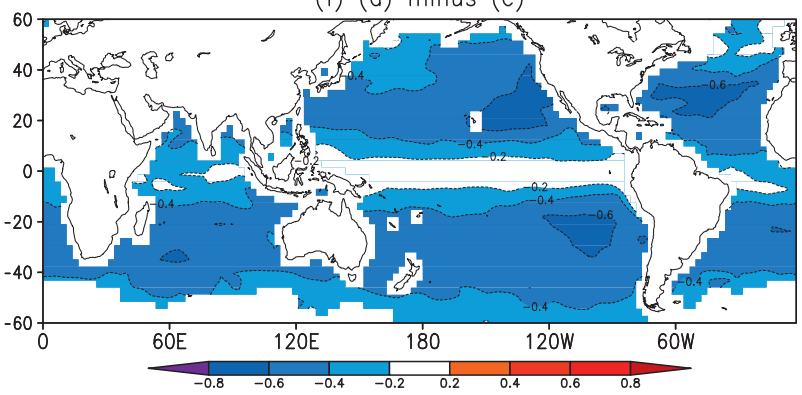

FIG. 11. Pointwise and simultaneous correlations between the monthly LHF and SST anomalies in the (a) CGCM and (b) AGCM. (d),(e) As in (a),(b), but for the monthly LHF and SST tendency. The zero contours are not plotted. The colored regions are statistically significant at the $5 \%$ level using the $t$ test. (c),(f) The differences [(a) - (b)] and [(d) - (e)], respectively. Values between -0.2 and 0.2 are not plotted.

\section{2) LATENT HEAT FLUX CORRELATIONS WITH SST AND SST TENDENCY}

The simultaneous correlation between an atmospheric variable and SST, as well as between an atmospheric variable and SST tendency, can be used to analyze the relative importance of atmospheric forcing and SST forcing (Wu et al. 2006). We demonstrate that decomposition into SST-forced and weather noise components allows further understanding. Figure 11 shows the local LHF correlations with SST and SST tendency. The results are consistent with those shown in Fig. 7 of $\mathrm{Wu}$ et al. (2006), an indication that such relationships may be model independent. Both the CGCM and AGCM simulate the significantly positive correlation between the LHF (positive upward) and SST in the equatorial central and eastern Pacific and midlatitude Atlantic, representing damping of SST by the LHF. The AGCM correlation is due to the
SST-forced LHF, since the weather-noise LHF is uncorrelated with the SST. The differences between CGCM and AGCM in Fig. 11c represent the LHF-related local weather-noise forcing of SST in the CGCM, similar to the results for precipitation described above.

A negative LHF-SST tendency correlation in the tropical oceans is simulated in both the CGCM and AGCM (Figs. 11d,e), corresponding to a cooling tendency for enhanced evaporation. The differences between the CGCM and AGCM in Fig. 11f again represent the effect of weather-noise LHF forcing of the SST tendency in the CGCM, but not the AGCM. The nonzero LHF-SST tendency correlation in the tropics of the AGCM (Fig. 11e) is again entirely due to the SST-forced LHF, as the weather noise in the AGCM is uncorrelated with the SST tendency. In the tropics, Fig. 11e shows that the SST-forced LHF is a skillful predictor of the coupled SST evolution, even without coupling. This 
effectively shows that SST is a skillful predictor of SST evolution, consistent with the well established usefulness of statistical prediction models of ENSO. The roles of the LHF response to local SST variability and, through teleconnections, to remote SST, are not, however, readily distinguishable.

\section{Conclusions}

A brief summary is provided, and we conclude by discussing some potential applications.

\section{a. Summary}

The relationship between coupled atmosphere-ocean GCM simulations and SST-forced atmospheric GCM simulations was reexamined in a perfect model framework using the CCSM3. A century-length coupled simulation with constant external forcing provided synthetic observations. Monthly mean output data were analyzed.

The time-dependent signal (the response to the SST forcing) was taken as the ensemble mean from an ensemble of uncoupled (atmosphere-land) simulations forced by the SST from the coupled simulation. Atmospheric weather noise in the coupled and uncoupled simulations was calculated by subtracting the signal from the respective simulations.

Two questions were addressed, both related to the issue of understanding the origin of previously described differences between the statistics of anomalies in the coupled and uncoupled simulations. First, we tested whether the statistics of the weather noise were the same in the coupled and uncoupled simulations, assuming that the signal was the same in both. After correcting for the finite number of members in the uncoupled ensemble, we found that the weather-noise variances in the coupled and uncoupled simulations were statistically indistinguishable, as were the variances in separate ensemble members.

Second, we tested if the SST-forced signal was the same in the coupled and uncoupled simulations. One test assumed that the weather noise was spatially uncorrelated for sufficiently large length scales. Our test was to regress a previously examined IMR index against various fields. This test was positive-the structure of the signal was the same in the coupled and uncoupled simulations except close to the index region, where the interference between weather noise and signal in the CGCM plays a role.

Our results provide clear evidence that the SSTforced response in the coupled and uncoupled simulations (CCSM3 and CAM3) is the same, and that the weather noise statistics are the same as well. The differences in the variances of various fields in the coupled and uncoupled simulations are shown to be due to constructive or destructive interference between the signal and noise in the coupled simulation, but no interference between the signal and noise in the uncoupled simulations. The origin of at least part of the signal in the coupled simulation can then be attributed to forcing by the weather noise; on the other hand, specifying the SST in the uncoupled simulation eliminates the mechanism relating the signal to the noise. This picture corresponds exactly to the one presented in an idealized stochastically forced model by BB98, where it was assumed that the statistics of the specified noise were the same in the coupled and uncoupled models. It is an open question as to whether these results will be confirmed by other models.

We extend the results of BB98 to global models, in which the response to remote SST through atmospheric teleconnections is part of the SST-forced response. Discrepancies between the coupled and uncoupled simulations forced by the coupled SST are then attributable only to atmospheric weather-noise forcing the ocean in the coupled simulation.

Our results appear to disagree with some results presented previously, where substantial differences were found between the observed forced response and simulated forced response using observed SST. Assuming that the behavior we have found applies to other models, potential explanations for the different conclusions include model bias and insufficient or inaccurate observational data.

Some deficiencies in the experimental design, mainly in the specification of the boundary conditions for the uncoupled simulation, were noted and hopefully will be alleviated in the future. First, because the specified SST dataset was created from a single value for each grid box using atmospheric model output, it contained errors in grid boxes that included both ocean and other surface types (i.e., land and/or sea ice). Second, since land surface conditions and sea ice temperature (but not concentration) were free to vary in the uncoupled simulations, the forced response due to the evolution of land and sea ice conditions that occurred in the coupled simulation is not represented in the uncoupled simulations, and hence is not removed from the inferred weather noise.

\section{b. Potential applications}

One potential advance that could follow from our results is a better understanding of the mechanisms of climate predictability beyond the limit of deterministic weather prediction. According to the signal/noise decomposition, only the SST and externally forced signal can be viewed as potentially predictable at longer time 
scales. If the SST is itself forced by the weather noise, then the effect of the weather noise can only be to degrade the SST prediction, that is, to destroy predictability. The rate at which the SST predictability is destroyed will depend on the competition between the weather-noise forcing and the initial-value problem evolution of the SST signal incorporating ocean heat capacity and dynamics, and atmosphere-ocean coupling.

Another application of our results could be for model verification. An uncoupled model ensemble forced by observed SST and externally forcing will produce an estimate of the signal in various fields. These signals could then be used to infer the weather noise in the model and in observations. The model could then be said to be more or less realistic to the extent that its weather-noise variance resembles or differs from the estimated observed weather-noise variance.

A third application could be with regard to dynamical downscaling. We can view the uncoupled AGCM in the perfect model simulations as "same-scaling," analogous to dynamical downscaling using an atmospheric model forced by specified SST. In the perfect model case, the statistics of the same-scaled precipitation variability are different from the correct (CGCM) statistics. Consequently, the same-scaled results could produce misleading results concerning precipitation extremes, at least over ocean. Therefore, we suggest that it would be useful to devise experiments to evaluate specified-SST dynamical downscaling in a perfect model configuration.

A final application is in model development. Tuning adjustable parameters in physical parameterizations is a necessary step in the development of a coupled general circulation model. Tuning is commonly done to produce the most realistic response of the AGCM to observed SST, and the tuned AGCM is then coupled to the ocean without further change. If parameters in the AGCM component of a coupled model are tuned in climate mode (i.e., by verifying the statistics of long simulations against observed statistics) to agree with observed precipitation variance when forced by observed SST, an intrinsic lower precipitation variance bias will be built into the coupled model, assuming the coupled model produces realistic SST statistics. This is because the weather-noise variance in the uncoupled model in climate mode is not correlated with the SST. To the extent that the precipitation variance reflects the surface heat flux variance, the tuning would lead to deficient SST variance in the coupled model. Thus the statistics of the SST-forced AGCM should not necessarily be tuned to best match the observed statistics. One approach to alleviate the bias introduced in our example would be to tune the uncoupled AGCM precipitation variance to agree with observations in short-range retrospective weather predictions, such as in reanalysis mode (in keeping with "seamless prediction") (Brunet et al. 2010). In the deterministic limit, the weather noise is predicted accurately and hence correctly related to the SST, and the tuned AGCM will give realistic precipitation variance in the coupled model. Another approach would be to tune in the context of the coupled model.

Acknowledgments. The contributions of Chen, Colfescu, and Schneider were supported by NSF Grants ATM-0653123 and AGS-1137902. Schneider was also supported by NSF Grants ATM-0830068 and ATM0830062, NOAA Grant NA09OAR4310058, and NASA Grant NNX09AN50G. Kirtman was supported by NSF Grant AGS-1137911. The NCAR CISL provided computer resources for the simulations. Data analyses and plotting were done using GrADS.

\section{REFERENCES}

Barsugli, J. J., and D. S. Battisti, 1998: The basic effects of atmosphere-ocean thermal coupling on midlatitude variability. J. Atmos. Sci., 55, 477-493.

Bhatt, U. S., M. A. Alexander, D. S. Battisti, D. D. Houghton, and L. A. Keller, 1998: Atmosphere-ocean interaction in the North Atlantic: Near-surface climate variability. J. Climate, 11, 1615-1632.

Bladé, I., 1997: The influence of midlatitude ocean-atmosphere coupling on the low-frequency variability of a GCM. Part I: No tropical SST forcing. J. Climate, 10, 2087-2106.

Bretherton, C. S., and D. S. Battisti, 2000: An interpretation of the results from atmospheric general circulation models forced by the time history of the observed sea surface temperature distribution. Geophys. Res. Lett., 27, 767-770.

Brunet, G., and Coauthors, 2010: Collaboration of the weather and climate communities to advance subseasonal-to-seasonal prediction. Bull. Amer. Meteor. Soc., 91, 1397-1406.

Collins, W. D., and Coauthors, 2006a: The Community Climate System Model version 3 (CCSM3). J. Climate, 19, 2122-2143.

, P. J. Rasch, B. A. Boville, J. J. Hack, J. R. McCaa, D. L. Williamson, and B. P. Briegleb, 2006b: The formulation and atmospheric simulation of the Community Atmosphere Model version 3 (CAM3). J. Climate, 19, 2144-2161.

Danabasoglu, G., W. G. Large, J. J. Tribbia, P. R. Gent, B. P. Briegleb, and J. C. McWilliams, 2006: Diurnal coupling in the tropical oceans of CCSM3. J. Climate, 19, 2347-2365.

Deser, C., A. Capotondi, R. Saravanan, and A. S. Phillips, 2006: Tropical Pacific and Atlantic climate variability in CCSM3. J. Climate, 19, 2451-2481.

Dickinson, R. E., K. W. Oleson, G. Bonan, F. Hoffman, P. Thornton, M. Vertenstein, Z.-L. Yang, and X. Zeng, 2006: The Community Land Model and its climate statistics as a component of the Community Climate System Model. J. Climate, 19, 2302-2324.

Fan, M., and E. K. Schneider, 2012: Observed decadal North Atlantic tripole SST variability. Part I: Weather noise forcing and coupled response. J. Atmos. Sci., 69, 35-50.

Folland, C. K., J. Shukla, J. Kinter, and M. J. Rodwell, 2002: The Climate of the Twentieth Century Project. CLIVAR Exchanges, 
Vol. 7 (2), International CLIVAR Project Office, Southampton, United Kingdom, 37-39.

Frankignoul, C., 1999: A cautionary note on the use of statistical atmospheric models in the middle latitudes: Comments on "Decadal variability in the North Pacific as simulated by a hybrid coupled model." J. Climate, 12, 1871-1872.

Gallimore, R. G., 1995: Simulated ocean-atmosphere interaction in the North Pacific from a GCM coupled to a constant-depth mixed layer. J. Climate, 8, 1721-1737.

Gates, W. L., and Coauthors, 1999: An overview of the results of the Atmospheric Model Intercomparison Project (AMIP I). Bull. Amer. Meteor. Soc., 80, 29-55.

Hasselmann, K., 1976: Stochastic climate models. Part I: Theory. Tellus, 28, 473-485.

Holland, M. M., C. M. Bitz, E. C. Hunke, W. H. Lipscomb, and J. L. Schramm, 2006: Influence of the sea ice thickness distribution on polar climate in CCSM3. J. Climate, 19, 2398-2414.

Hurrell, J., G. A. Meehl, D. Bader, T. L. Delworth, B. Kirtman, and B. Wielicki, 2009: A unified modeling approach to climate system prediction. Bull. Amer. Meteor. Soc., 90, 1819-1832.

Kirtman, B. P., and J. Shukla, 2002: Interactive coupled ensemble: A new coupling strategy for CGCMs. Geophys. Res. Lett., 29, 1367-1370.

— D. M. Straus, D. Min, E. K. Schneider, and L. Siqueira, 2009: Toward linking weather and climate in the interactive ensemble NCAR climate model. Geophys. Res. Lett., 36, L13705, doi:10.1029/2009GL038389.

— , E. K. Schneider, D. M. Straus, D. Min, and R. Burgman, 2011: How weather impacts the forced climate response. Climate Dyn., 37, 2389-2416.

Kitoh, A., and O. Arakawa, 1999: On overestimation of tropical precipitation by an atmospheric GCM with prescribed SST. Geophys. Res. Lett., 26, 2965-2968.

Kumar, K., M. Hoerling, and B. Rajagopalan, 2005: Advancing dynamical prediction of Indian monsoon rainfall. Geophys. Res. Lett., 32, L08704, doi:10.1029/2004GL021979.

Leith, C. E., 1973: The standard error of time-averaged estimates of climatic means. J. Appl. Meteor., 12, 1066-1069.
Manabe, S., and R. J. Stouffer, 1996: Low-frequency variability of surface air temperature in a 1000-year integration of a coupled atmosphere-ocean-land surface model. J. Climate, 9, 376-393.

Rowell, D. P., C. K. Folland, K. Maskell, and M. N. Ward, 1995: Variability of summer rainfall over tropical North Africa (1906-92): Observations and modelling. Quart. J. Roy. Meteor. Soc., 121, 669-704.

Saravanan, R., 1998: Atmospheric low-frequency variability and its relationship to midlatitude SST variability: Studies using the NCAR Climate System Model. J. Climate, 11, 1386-1404.

Schneider, E. K., and M. Fan, 2007: Weather noise forcing of surface climate variability. J. Atmos. Sci., 64, 3265-3280.

— and - 2012: Observed decadal North Atlantic tripole SST variability. Part II: Diagnosis of mechanisms. J. Atmos. Sci., 69, 51-69.

Wang, B., Q. Ding, X. Fu, I. Kang, K. Jin, J. Shukla, and F. DoblasReyes, 2005: Fundamental challenge in simulation and prediction of summer monsoon rainfall. Geophys. Res. Lett., 32, L15711, doi:10.1029/2005GL022734.

Wu, R., and B. P. Kirtman, 2004: Impacts of the Indian Ocean on the Indian summer monsoon-ENSO relationship. J. Climate, 17, 3037-3053.

- - , and K. Pegion, 2006: Local air-sea relationship in observations and model simulations. J. Climate, 19, 49144932.

- — , and - 2007: Surface latent heat flux and its relationship with sea surface temperature in the National Centers for Environmental Prediction Climate Forecast System simulations and retrospective forecasts. Geophys. Res. Lett., 34, L17712, doi:10.1029/2007GL030751.

Wu, Z., E. K. Schneider, and B. P. Kirtman, 2004: Causes of low frequency North Atlantic SST variability in a coupled GCM. Geophys. Res. Lett., 31, L09210, doi:10.1029/2004GL019548.

Xie, S.-P., K. Hu, J. Hafner, H. Tokinaga, Y. Du, G. Huang, and T. Sampe, 2009: Indian Ocean capacitor effect on Indo-western Pacific climate during the summer following El Niño. J. Climate, 22, 730-747. 